\title{
Grandir en harmonie: Document de références
}

Population Council

Follow this and additional works at: https://knowledgecommons.popcouncil.org/departments_sbsr-rh

Part of the Community Health and Preventive Medicine Commons, Demography, Population, and Ecology Commons, Family, Life Course, and Society Commons, Health Communication Commons, International Public Health Commons, and the Medicine and Health Commons How does access to this work benefit you? Let us know!

\section{Recommended Citation}

"Grandir en harmonie: Document de références." Dakar: Population Council, 2007. 


\section{crandir en harmonie}

\section{Document de références}

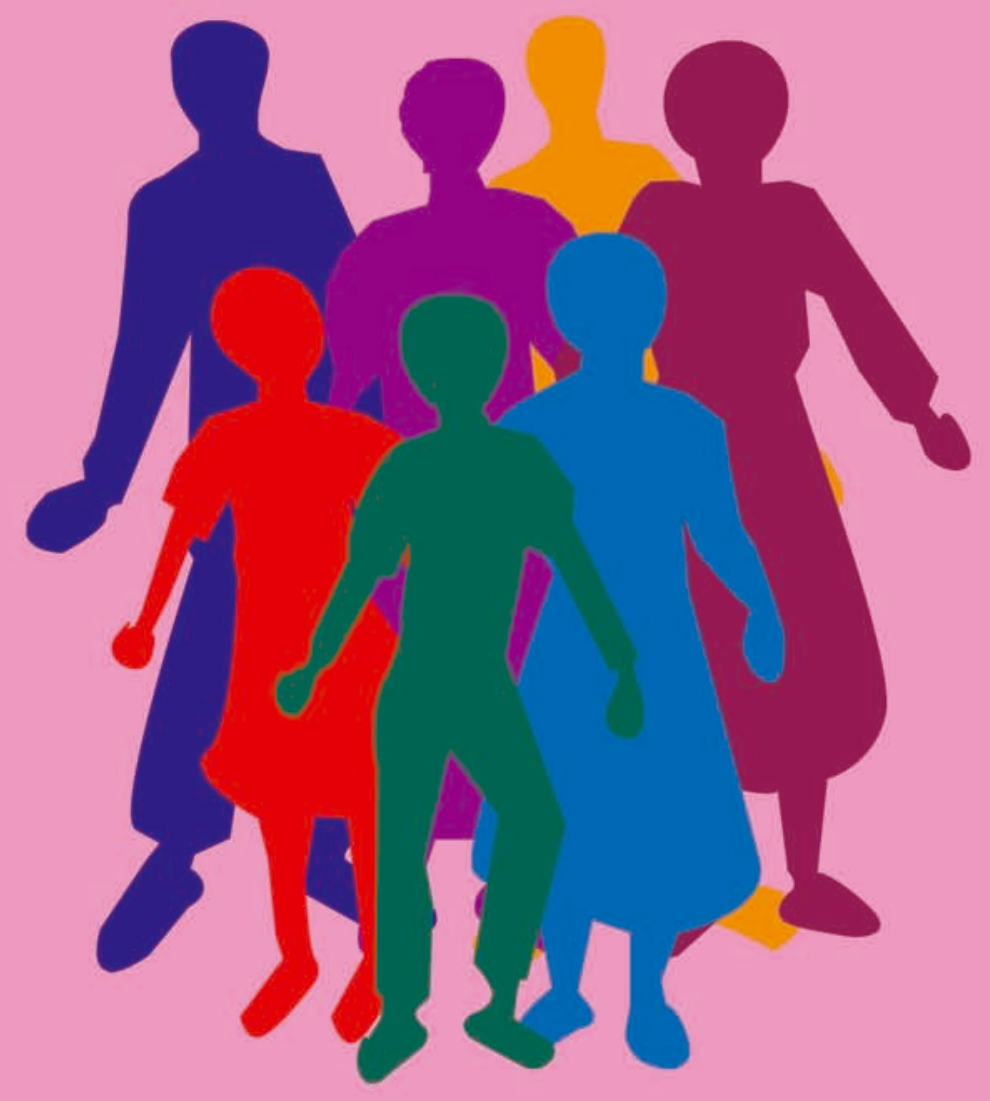




\section{Sommaire}

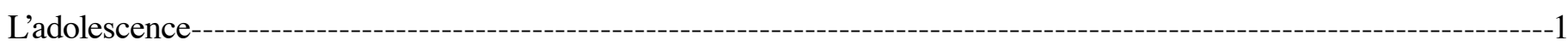

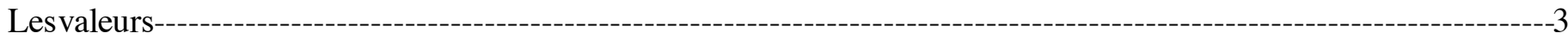

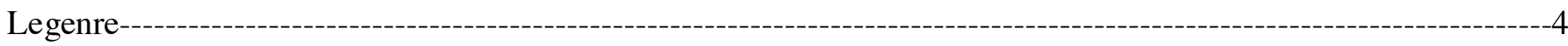

LesMutilationsGénitalesFéminines(MGF)---

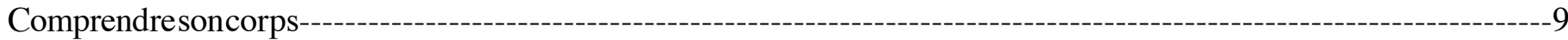

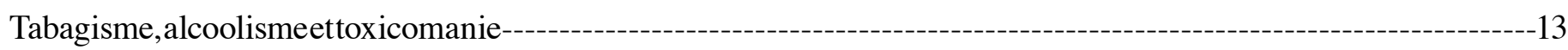

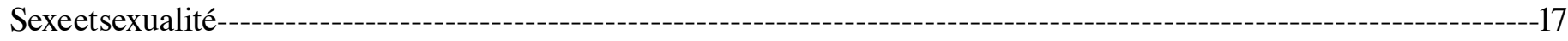

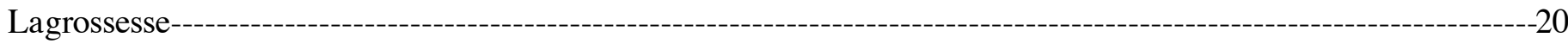

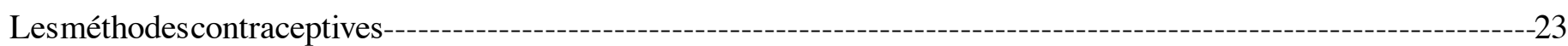

LesInfectionsSexuellementTransmissibles(IST)--

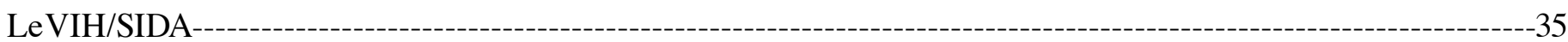




\section{L’adolescence}

\section{Qu'est-ce que l'adolescence?}

Quand les filles et les garçons atteignent l'âge de 10 ou 11 ans, leurs corps d'enfants commencent à changer pour ressembler davantage à celui d'un adulte. Ce changement est appelé puberté. Il arrive à partir de l'âge de 10 ans jusqu'à l'âge de 19 ans environ. Cette période de la vie est appelée adolescence.

Le corps va produire des ovules chez la fille et du sperme chez le garçon. Ces derniers sont alors capables d'enfanter.

\section{Principaux changements physiques/physiologiques}

Pendant cette période, la taille et le poids augmentent. On note d'autres transformations:

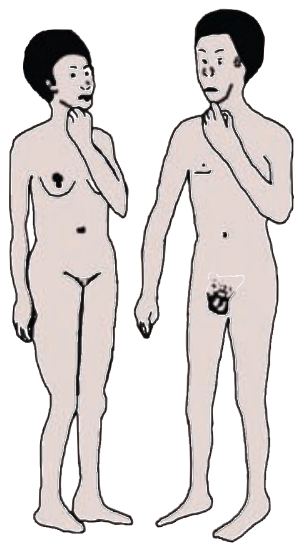

\begin{tabular}{|l|l|}
\hline Chez la fille & Chez le garçon \\
\hline Développement des seins & Augmentation de la taille \\
\hline Augmentation accélérée de la taille & Elargissement des épaules \\
\hline Augmentation du poids & Augmentation du poids (développement de la musculature) \\
\hline Apparition des premières règles & Premières éjaculations \\
\hline $\begin{array}{l}\text { Apparition des poils pubiens et sous les } \\
\text { aisselles }\end{array}$ & $\begin{array}{l}\text { Apparition des poils au niveau du pubis, sous les aisselles } \\
\text { et à la face }\end{array}$ \\
\hline Développement des organes génitaux & Développement des organes génitaux \\
\hline Développement du bassin & Pollutions nocturnes \\
\hline \multirow{2}{*}{ Acné } & Mue de la voix \\
\cline { 2 - 2 } & Acné \\
\hline
\end{tabular}

\section{Principaux changements psychiques/émotionnels}

L'adolescent recherche son identité, il veut s'affirmer, se distinguer des autres et plus particulièrement de ses parents. Il fait plus attention à sa façon de s'habiller en affinant son "look". La manière dont les autres le jugent est importante pour lui. Certains deviennent plus religieux pendant que d'autres veulent expérimenter de nouvelles valeurs, de nouvelles expériences.

Les besoins sexuels se réveillent chez l'adolescent. Ces besoins sont d'abord dirigés vers son propre corps: c'est la découverte de la masturbation. Puis rapidement l'adolescent se sent attiré par la personne de l'autre sexe. Le garçon commence à admirer la fille et vice versa, à avoir des sentiments romantiques et se sentir lunatique.

Perte de la relation de dépendance envers les parents et les autres adultes

Acceptation de soi comme une personne pleine, digne d'amour

Prise de conscience de la perte du corps de l'enfant et adaptation au nouveau corps

Développement de l'aptitude à l'abstraction

Recherche de sa propre identité

Tendance à agir et à se comporter comme un adulte

Comportements sexuels transitoires (jeux sexuels tels que baisers sur la bouche, masturbation, caresses...)

Sautes d'humeur 


\section{Principaux changements relationnels et sociaux au cours de l'adolescence}

C'est le moment de la vie de clubs, d'associations de quartiers, de foyers... Le fait d'appartenir à un groupe est important pour l'adolescent. Il se sent intégré parmi ses pairs avec lesquels il veut refaire le monde en critiquant la société.

Il est donc souvent en conflit avec les adultes de façon générale et avec ses parents plus particulièrement. Cette période d'opposition mène l'adolescent vers la maturité.

\begin{tabular}{|l|}
\hline Développement des bandes de copains, copines \\
\hline Recherche d'identification à un groupe \\
\hline Tendance à réduire la dépendance économique vis-à-vis des adultes \\
\hline Développement de l'identité sociale et sexuelle. \\
\hline
\end{tabular}

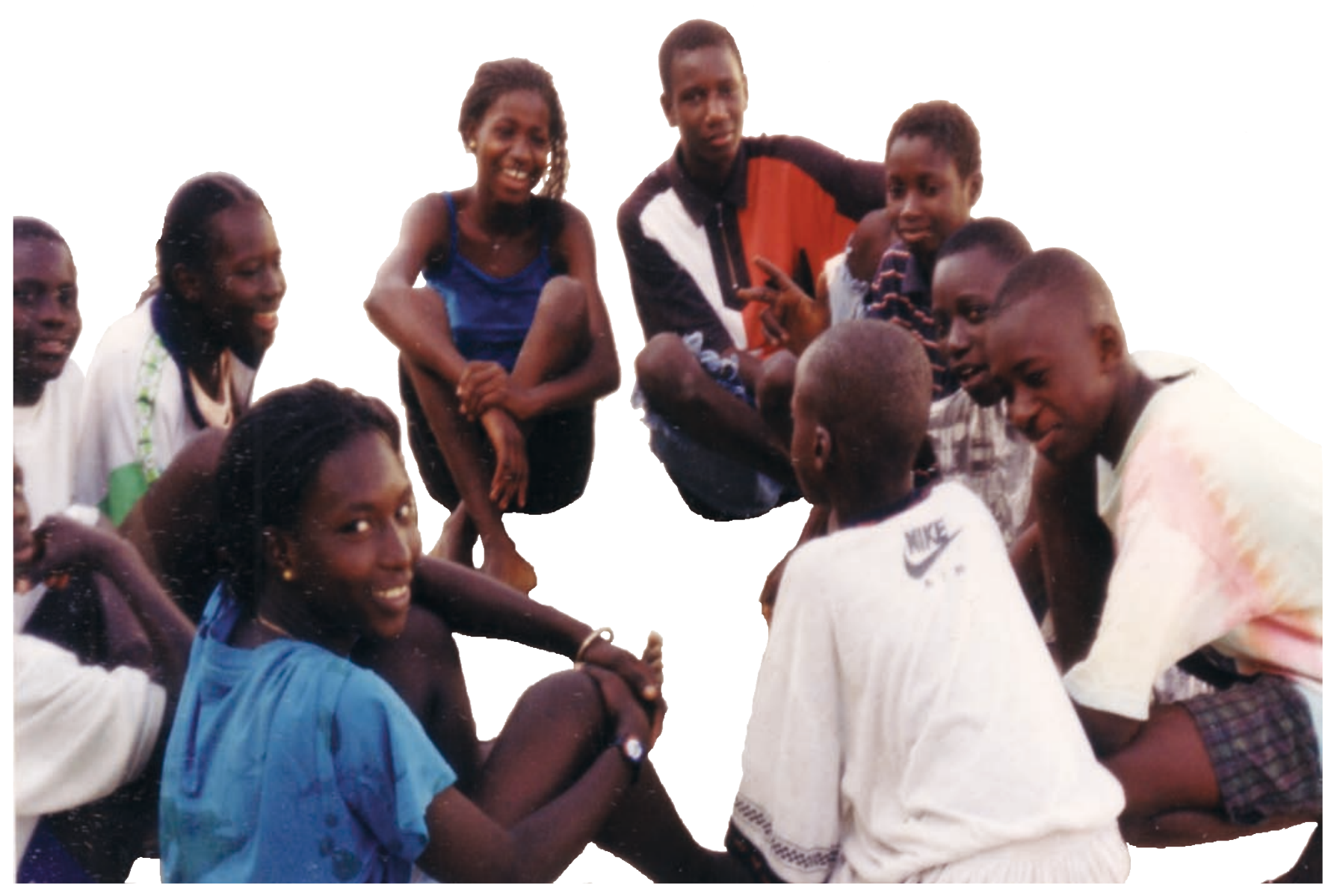




\section{Les valeurs}

Les valeurs sont ce qui donnent sens et direction à notre vie. Elles correspondent à ce qui nous importe le plus. Nos actes doivent être en harmonie avec nos valeurs pour nous donner un sentiment de cohérence et de plénitude. Les valeurs font également partie intégrante de la manière dont nous entrons en relation avec les autres et avec le monde. Elles contribuent à la réussite personnelle aussi bien qu'à l'harmonie sociale.

Les valeurs constituent tout ce que l'individu considère subjectivement comme étant vraies ou importantes. Elles peuvent être soit des préférences ou des principes. Les préférences sont des choix personnels qui sont subjectifs et qui peuvent changer à tout moment. Par contre les principes, comme l'honnêteté, la compassion... sont conséquents (logiques), universels, transculturels et objectifs. La grande différence entre les deux types de valeurs est que les préférences sont des choses "à avoir", alors que les principes sont des "manières d'être".

\section{Comme valeurs on peut citer:}

(1) la paix;

(1) respect;

(1'amour;

la tolérance;

(1) le bonheur;

() la responsabilité;

- la coopération;

(1'humilité;

(.) l'honnêteté;

(1) la simplicité;

(1) la liberté;

(1) l'unité.

Ces valeurs universelles forgent le caractère qui engendre les comportements bénéfiques à l'individu, aux autres et à la communauté. Elles contribuent au bien-être de tous, empêchent le mal à l'individu et à la société. Elles sont l'essence des rapports sains.

Les jeunes (et même les enfants d'aujourd'hui) ont besoin de voir l'effet de leurs comportements et de leurs choix. Ils doivent apprendre en conséquence à effectuer des choix en étant conscients de leurs effets induits. Si les jeunes d'aujourd'hui doivent intégrer ces valeurs non seulement dans leur vie d'adulte, mais dans la société en général, il est alors important qu'ils connaissent la notion de la responsabilité sociale et qu'ils aient des modèles d'adultes qui soient l'exemple de ces valeurs. 


\section{Le genre}

Le sexe est biologique et génétique. Quand on dit sexe, on décrit le corps physique: je suis une fille si j'ai des seins, un vagin... Je suis un garçon si j'ai des testicules et un pénis.

Selon qu'on est une fille ou un garçon, notre société nous attribue des valeurs, des rôles et des responsabilités différents. Par exemple: on dit que les filles sont émotives, les garçons rationnels; l'homme est la principale source de revenus de la famille, la femme est la gardienne du foyer... Les filles doivent avoir des comportements, des aptitudes et des pratiques différents des garçons: les jeunes garçons jouent dehors, tandis que les jeunes filles restent à la maison et aident leur maman dans les travaux domestiques.

Le genre est créé par chaque société. Il décrit la manière dont les filles et les garçons, les hommes et les femmes et tous les groupes

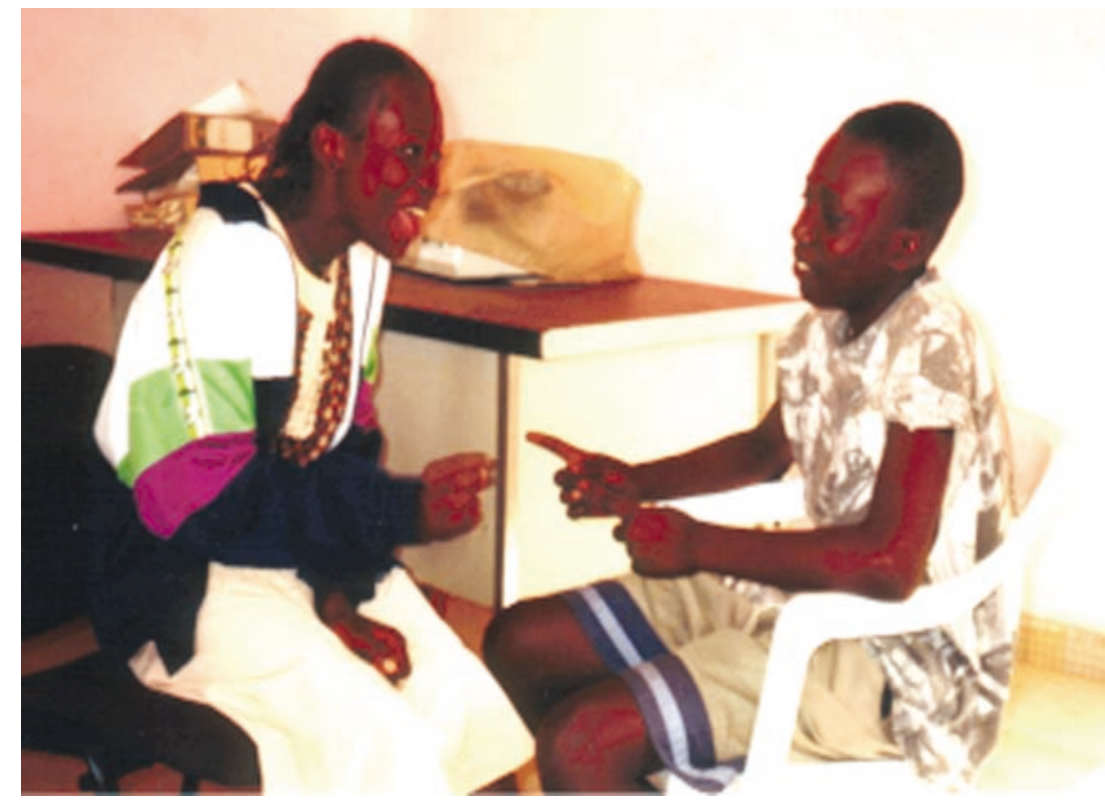
dans la communauté doivent se comporter. Le genre diffère d'une communauté à l'autre.

Quand on parle de "l'approche genre", on veut analyser les inégalités et les injustices entre les différents groupes sociaux (hommes/femmes; enfants/ adultes...) et pouvoir offrir à ces groupes les mêmes chances de s'épanouir, se développer et aider au développement de leur société.

\section{Principes de l'approche genre:}

Egalité Homme/femme à la naissance

(2) Tous les Hommes naissent égaux.

(1) Egalité de chance dans la vie, les hommes et les femmes ont les mêmes chances dans la vie, particulièrement en ce qui concerne le travail.

(2) Promotion du statut de la femme

(1) La charge de travail des femmes est très lourde et pourtant la valeur de ce travail n'est pas reconnue. Leur statut et rôle dans la société ne sont pas valorisés.

\section{Renforcement du pouvoir de décision et du pouvoir économique des femmes}

Beaucoup de femmes ne peuvent pas prendre des décisions qui concernent directement leur vie, celle de leur foyer ou de leur cité. Elles n'ont pas de ressources. Elles ont du mal à s'épanouir. Les femmes doivent prendre part aux décisions importantes de leur vie, pouvoir entreprendre des actions pour leur propre développement. Pour cela, il faut qu'elles soient formées et que leurs pouvoirs soient renforcés.

\section{Violences conjugales}

Les femmes subissent des violences quotidiennes au sein de leurs foyers. Les populations doivent savoir que de telles pratiques sont interdites par la loi et empêchent l'épanouissement des femmes. 


\section{Mariages précoces}

Les mariages précoces ont des conséquences négatives sur les filles notamment sur leur santé (grossesses précoces, accouchements difficiles, infection au VIH/SIDA...), leur éducation et leur formation.

\section{Education des filles}

Beaucoup de filles ne sont pas inscrites à l'école parce ce qu'elles sont destinées à s'occuper des travaux ménagers, à seconder la mère dans l'entretien du foyer...

\section{Accès des femmes à la terre}

Souvent, les femmes n'ont pas de droit de propriété sur les terres qu'elles exploitent.

\section{Quelques domaines clés d'application du genre:}

\section{Le renforcement des capacités économiques des femmes}

Dans nos pays, les femmes constituent un atout majeur de la force de travail. Elles sont dans les secteurs clés du développement social et économique (secteur commercial informel, production agricole, rôles de mères et d'éducatrices). Pourtant elles subissent des discriminations au niveau de l'enseignement, de l'embauche, de l'accès au crédit, du droit de posséder ou d'hériter d'une propriété foncière. L'accès à un revenu personnel donne aux femmes le sens de l'autonomie et la capacité de prendre des décisions au sein de leur foyer.

\section{La promotion des droits humains}

Les droits fondamentaux des femmes et des fillettes font partie des droits universels de la personne. Les femmes et les filles doivent accéder à la santé, à l'éducation, aux ressources, elles doivent participer à la prise de décision... La scolarisation des filles est essentielle. Les populations en général, et les femmes en particulier doivent être informées sur ces droits fondamentaux.

\section{Les Nouvelles Technologies de l'Information et de la Communication (NTIC)}

Les NTIC incluent les ordinateurs, le logiciel de la bureautique, les jeux informatiques, les systèmes de communications des données complexes, les applications simples d'internet, les services de communications basiques et avancées, la radio et la télévision. Former les femmes et les filles à tous ces outils, c'est renforcer leur capacité de développement et leur épanouissement. Cela leur permet également de trouver des emplois et des opportunités économiques.

\section{La Gouvernance}

C'est une participation égale des femmes et des hommes à la prise de décision et dans l'élaboration des politiques. Ce qui est nécessaire au renforcement de la démocratie et à son bon fonctionnement.

\section{La Santé de la Reproduction}

La santé de la reproduction se rapporte au bien-être physique, mental et social, pour tout ce qui concerne l'appareil génital, ses fonctions et son fonctionnement. Une personne est capable et libre de faire un enfant aussi souvent ou aussi peu souvent qu'elle le désire. Les hommes et les femmes ont le droit d'être informés et d'utiliser la méthode de planification familiale de leur choix. Ils ont le droit d'avoir accès à des services de santé. La femme doit pouvoir décider de quand se marier, avec qui et du nombre d'enfants qu'elle souhaiterait avoir. Tout ceci améliore la qualité de la vie et les relations interpersonnelles. 


\section{Les Mutilations Génitales Féminines (MGF)}

Dans certaines cultures, on coupe certaines parties de l'appareil génital des filles. On parle de mutilation génitale féminine, de circoncision féminine ou encore d'excision. Il y a trois types d'opérations:

La clitoridectomie: le clitoris et son capuchon sont coupés;

() L'excision: le clitoris et les petites lèvres sont coupés totalement ou partiellement;

(1) L'infibulation: l'excision du clitoris et des petites lèvres est complétée par l'ablation des grandes lèvres. Les deux côtés de la vulve sont alors cousus de telle façon qu'il ne reste qu'une petite ouverture pour l'écoulement des urines et des règles. La vulve laisse la place à une cicatrice très dure, qu'il faudra inciser au moment du mariage ou de la naissance d'un enfant.

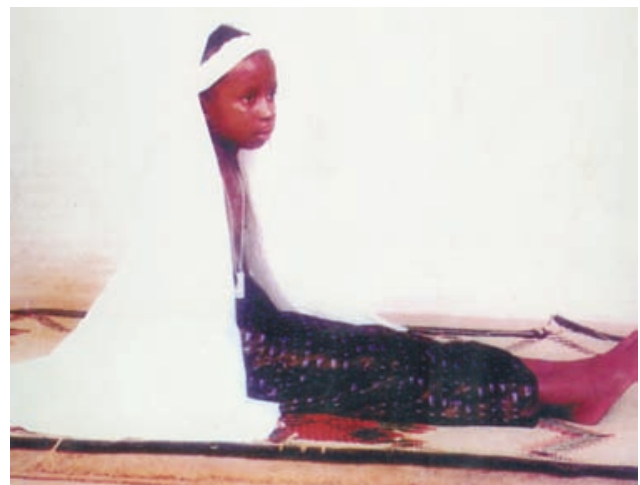

L'excision est surtout pratiquée en Afrique de l'Ouest et en Egypte tandis que l'infibulation est surtout pratiquée en Afrique de l'Est.

On ne peut pas comparer la circoncision chez l'homme aux mutilations génitales féminines. La circoncision c'est ablation du prépuce du pénis sans endommager le pénis lui-même.

L'équivalent chez l'homme de la clitoridectomie serait l'amputation de la plus grande partie du pénis. L'équivalent chez l'homme de l'infibulation serait l'enlèvement ou "le rasage" total du pénis, les racines de son tissu sensitif, et une partie de la peau des testicules.

\section{Raisons de l'excision: la dimension sociale}

Les communautés qui pratiquent les MGF donnent différentes raisons:

() Augmenter la fécondité des femmes;

(.) Assurer la pureté de la femme;

(1) Réduire le désir sexuel chez les femmes;

(1) Assurer la fidélité conjugale;

(2) Préserver la virginité de la fille jusqu'au mariage;

(1) Servir de rite de passage de l'adolescence au statut de femme;

- Sauvegarder les traditions culturelles et religieuses (certains pensent que les MGF sont imposées par l'Islam ou par les ancêtres);

(.) Servir comme une certaine forme de traitement médical (dans certaines ethnies, on pense que le clitoris est source de maladies, présence de vers...).

Comme dans d'autres domaines qui concernent la vie familiale (le mariage par exemple), la décision de faire subir une MGF à une fillette est généralement prise par les hommes (mari, père, aîné de la famille...)

\section{Conséquences de la pratique des MGF sur la Santé}

Les MGF constituent un problème majeur de santé publique dans la mesure où elles affectent la santé des fillettes et des femmes.

\section{Les complications immédiates}

On peut citer les douleurs, les chocs, les hémorragies, la rétention d'urine aiguë, les lésions des tissus, les brûlures à l'émission des urines, les risques de maladies à transmission sanguine comme l'hépatite B et le VIH/ SIDA (à cause de l'utilisation d'instruments tranchants au cours des mutilations collectives), ainsi que d'autres infections provoquant la fièvre, le tétanos, la gangrène, la septicémie et dans certains cas, entraînant la mort. 


\section{Les complications durables}

Les complications durables comprennent l'urination difficile, l'infection répétée des voies urinaires, les règles douloureuses, le neurone clitoridien, les rapports sexuels douloureux, le dysfonctionnement sexuel, le risque de maladies à transmission sanguine comme l'hépatite $\mathrm{B}$ et le VIH/SIDA (à cause de la fréquence des déchirures et des sutures au cours des accouchements et des lésions durant les rapports sexuels), les infections chroniques et les pertes blanches, la stérilité, les fistules vaginales, le travail prolongé ainsi que les conséquences psychologiques et sociales.

\section{Conséquences sur le plan sexuel et psychologique}

L'excision peut diminuer l'atteinte du plaisir sexuel de la femme. Le clitoris est un organe beaucoup plus sensible que le vagin; il remplit un rôle essentiel dans l'atteinte de l'orgasme. L'excision occasionne donc des frustrations de la part de la femme et en cas de complications graves, une tendance à éviter tout contact physique avec le sexe opposé (même avec son mari).

Les MGF peuvent aussi affecter l'image que les filles et les femmes ont d'elles-mêmes et réduire l'estime et la confiance en soi, en leur féminité.

Chez la petite fille la vue du sang et la douleur peuvent entraîner un traumatisme, allant de l'anxiété à la dépression. Les populations interprètent souvent ces signes comme la manifestation de mauvais esprits (rab). Des rituels traditionnels sont alors sensés chasser ces mauvais esprits.

Chez des femmes mariées ayant subi l'excision, les sage-femmes et gynécologues observent certains symptômes appelés “douleurs gynécologiques vagues". Elles peuvent être dues à l'accumulation de frustrations sexuelles, qui finit par créer des conflits avec leurs maris.

\section{Conséquences économiques:}

Les MGF peuvent réduire la capacité des femmes à participer à l'activité économique à cause des conséquences sur leur santé.

Les exiceuses tirent d'importants revenus supplémentaires de cette activité puisqu'elles sont payées. L'arrêt de l'excision signifie aussi l'arrêt de leur source de revenus. C'est pourquoi il faut leur offrir une activité rentable pour qu'elles puissent subvenir autrement à leurs besoins.

\section{Conséquences sociopolitiques:}

Les praticiennes ont un pouvoir au sein des communautés dans lesquelles elles vivent. Par l'exercice de leur métier, elles ont une position sociale valorisante transmise de génération en génération. En plus de ce rôle, les exciseuses assurent aussi les accouchements. Ce double statut leur donne de réelles opportunités politiques. Les exciseuses sont généralement des dirigeantes de la communauté et des militantes politiques importantes. $\mathrm{Si}$ on veut lutter contre les MGF, on doit tenir compte de cette dimension sociopolitique.

\section{Faut-il médicaliser les MGF?}

Certains ont proposé de faire l'intervention en milieu médical. L'anesthésie éviterait la douleur de l'intervention, les meilleures conditions d'hygiène préviendraient les infections, et la vigilance des personnels de santé, les hémorragies. Malheureusement, la mutilation ne serait pas évitée et la médecine ne sert pas à mutiler des individus, de surcroît des enfants.

En médicalisant les pratiques mutilatrices, on leur donne un caractère officiel. Ce qui risquerait de les maintenir. 


\section{Argumentaire religieux développé contre la pratique de l'excision}

Certaines communautés musulmanes justifient la pratique de l'excision par une obligation de l'Islam. Or des Islamologues font référence à des préceptes de l'Islam qui sont contre toute mutilation du corps humain et donc contre l'excision:

Notre Seigneur! Tu n'as pas créé tout ceci en vain (3:191);

(1) [Dieu] a bien fait tout ce qu'il a créé (32:7);

(1) [Le démon dit]: "Oui, je prendrai un nombre déterminé de tes serviteurs; je les égarerai et je leur inspirerai de vains désirs; je leur donnerai un ordre, et ils fendront les oreilles des bestiaux; je leur donnerai un ordre, et ils changeront la création de Dieu" (4:119).

On pourrait déduire de ces versets qu'on ne saurait supprimer des organes du corps humain sous prétexte de parfaire la nature humaine "la création divine étant par essence parfaite" ( 2 premiers versets). Changer la nature humaine équivaudrait à obéir au démon (3ème verset).

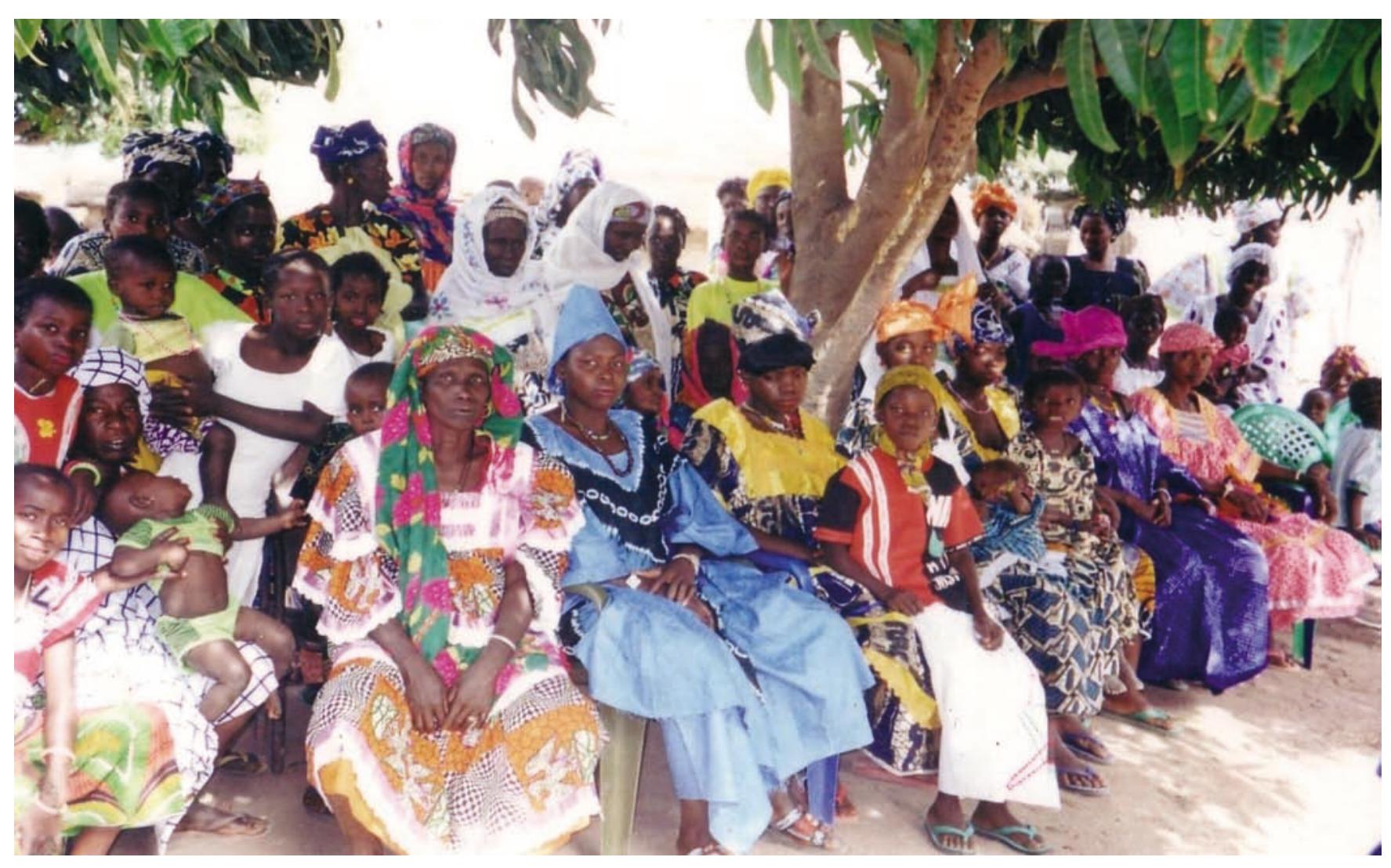




\section{Comprendre son corps}

L'adolescence est marquée par des changements du corps et une métamorphose psychologique et sociale.

Dans ce chapitre, il ne sera traité que des changements anatomiques et physiologiques. Pour les autres types de changements (psychologiques, relationnels et sociaux), voir chapitre précédent sur la définition de l'adolescence.

La puberté se situe en moyenne entre 13 et 15 ans. Elle survient en général un peu plus tôt chez les filles. Dans quelques cas, elle est dite précoce (elle arrive très tôt) ou tardive.

\section{La métamorphose anatomique}

$\mathrm{Au}$ moment de l'adolescence, les diverses parties du corps se trouvent profondément modifiées, et cela de façon très rapide.

Chez le garçon, la taille et le poids augmentent. La verge, les bourses et les testicules vont augmenter rapidement de taille et de volume pour atteindre, au bout de quelques mois, leurs mensurations quasi définitives. Chez le garçon, des poils poussent au niveau du pubis, sous les aisselles et sur la face, la voix mue.

Chez la fille, les lèvres et le clitoris augmentent de taille et de volume. Le vagin s'allonge, son aspect se modifie pour le rendre accessible à la pénétration, ce qui n'était pas le cas avant.

D'autres transformations secondaires apparaissent. Chez la fille: les seins se développent, des poils apparaissent au niveau du pubis, sous les aisselles.

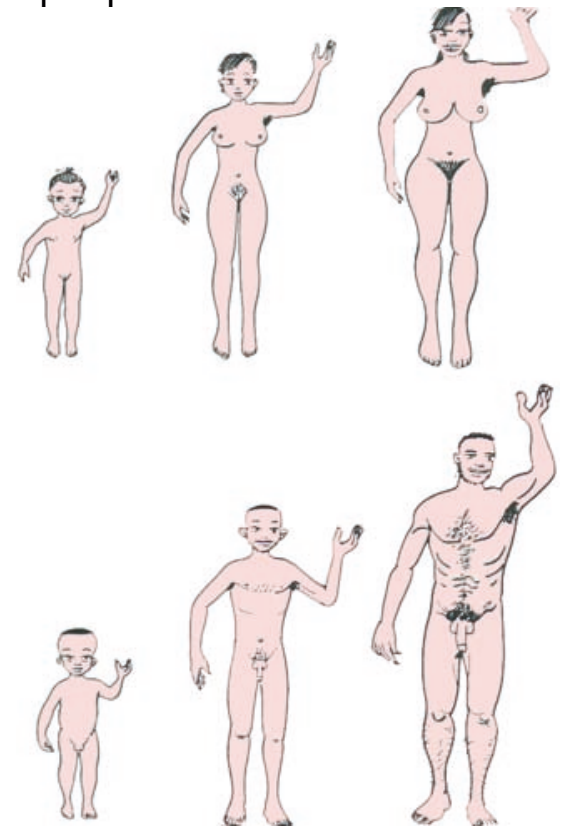

Ces caractères sexuels se transforment différemment selon l'individu en rapport avec des facteurs génétiques ou familiaux. Ils sont souvent source d'interrogations et d'angoisse chez l'adolescent.

\section{La métamorphose physiologique et glandulaire}

Les ovaires chez la fille, et les testicules chez le garçon se mettent à produire des hormones. C'est l'apparition des premières règles et des premières éjaculations.

\section{L’apparition des règles: la menstruation}

Chaque mois, un des deux ovaires lâche un ovule. L'ovule passe par la trompe de Fallope jusqu'à l'utérus; cela prend environ trois jours. Ce sont les jours les plus fertiles: si l'ovule rencontre un spermatozoïde pendant ce temps, il y aura fécondation donc grossesse.

Si l'ovule n'est pas fécondé, il est éliminé par le vagin en même temps que la muqueuse utérine remplie de sang: ce sont les règles. Elles durent 4 à 5 jours. La menstruation s'arrête d'habitude vers l'âge de 45 ans ou un peu plus tard. C'est la ménopause.

Les règles peuvent parfois causer des crampes, de la fatigue et/ou des douleurs dans le dos. C'est normal, la fille ne doit pas s'inquiéter pour cela, elle peut continuer à se livrer à ses occupations habituelles. Les femmes athlètes, par exemple, prennent part aux compétitions même si elles ont leurs règles, sans mauvaises conséquences. Il est spécialement important de bien se laver et de rester très propre pendant la période des règles, afin d'éviter tout frottement, toute irritation et toute odeur.

Pour absorber le flux menstruel, il existe plusieurs sortes de serviettes hygiéniques en coton. Elles doivent être lavées avec soin et séchées au soleil après l'emploi. On peut aussi acheter plusieurs sortes de serviettes hygiéniques jetables, ou des tampons que l'on insère dans le vagin. 


\section{L'éjaculation:}

La plupart des garçons ont fait l'expérience des érections matinales ou nocturnes. Ils sont souvent surpris par les premières éjaculations, surtout qu'elles surviennent la nuit. Ils se réveillent brutalement en sueur, avec une sensation d'humidité. Quand ils ne sont pas prévenus, ils éprouvent un malaise, une angoisse et une honte. Que va penser leur mère de ces tâches sur leurs draps? Cette gêne va se dissiper rapidement après les conversations avec les copains. Comme pour la fille, il faut rassurer le jeune garçon sur ce qui lui arrive et lui expliquer que c'est quelque chose de tout à fait naturel.

\section{Les organes génitaux}

La connaissance de notre corps est nécessaire pour la prévention de certaines maladies qui peuvent causer des problèmes à notre santé et à celle des autres. A ce titre, il a été jugé nécessaire d'insérer dans ce guide un chapitre sur l'anatomie de l'appareil génital de l'homme et de la femme. Ceci permettrait aux pairs-éducateurs ou à toute autre personne qui s'intéresserait à l'éducation sur les IST/SIDA d'avoir des informations utiles et de mieux comprendre les conséquences des IST sur notre organisme.

Dans cette partie, vous trouverez les schémas des organes génitaux de l'homme et de la femme, ainsi que des informations sur leur fonctionnement.

\section{Description des organes génitaux de l'homme}

L'appareil génital de l'homme comporte les organes génitaux externes et les organes génitaux internes.

\section{Les organes génitaux externes:}

$\Rightarrow$ Le pénis aussi appelé phallus (pénis en érection) ou verge. Il assure la sortie et le dépôt du sperme dans les voies vaginales de la femme. Il assure également l'évacuation de l'urine du corps. Le pénis a une grande importance pour le plaisir sexuel de l'homme. Il est le symbole de la virilité et de l'identité masculine. Le pénis est un organe extensible qui comprend trois parties: la racine, le corps et le gland qui est l'extrémité arrondie percée d'une ouverture. Le gland est la partie la plus sensible du pénis. Le gland chez un pénis au repos est recouvert d'une petite peau appelée prépuce. Dans certaines cultures, le prépuce est enlevé, c'est la circoncision;

$\Rightarrow$ Le scrotum ou bourse, est un sac de peau plus ou moins plissé, couvert de poils. Il se divise en deux compartiments situés sous le pénis. Chaque compartiment contient un testicule: lieu de reproduction des spermatozoïdes.

\section{Les organes génitaux internes:}

$\Rightarrow$ Les testicules sont situés dans le scrotum. C'est là que sont produits et stockés les spermatozoïdes. Le testicule gauche descend en général plus bas que le testicule droit dans le scrotum;

$\Rightarrow$ L'épididyme est composé de fins canaux enroulés qui ont l'aspect d'une virgule et qui recouvrent la partie supérieure du testicule. Il recueille et emmagasine les spermatozoïdes qui finissent de se développer et deviennent capables de féconder;

$\Rightarrow$ Le canal déférent, au nombre de deux, les canaux déférents prolongent chacun les épididymes. Ils pénètrent la cavité abdominale, entrent dans la prostate pour former les canaux éjaculateurs et rejoignent ensuite l'urètre. Le canal déférent conduit les spermatozoïdes de l'épididyme jusqu'à la hauteur de la prostate. La fonction du canal déférent est de stocker les spermatozoïdes jusqu'au moment où ils pourront être expulsés dans l'urètre lorsqu'il y a éjaculation;

$\Rightarrow$ Les vésicules séminales, au nombre de deux, produisent un liquide épais jaunâtre qui forme environ $20 \%$ du volume du sperme. Leurs sécrétions renferment des substances (sucre, vitamine C, prostaglandines...) qui servent à nourrir et à rendre mobiles les spermatozoïdes;

$\Rightarrow$ La prostate, est une glande située au-dessous de la vessie, donnant sur l'urètre. Elle secrète un liquide d'apparence laiteuse qui s'écoule dans les canaux éjaculateurs par de petites ouvertures lors de l'éjaculation. Ces sécrétions forment la plus grande partie du volume du sperme, dilue les spermatozoïdes, leur donne leur mobilité et un environnement favorable;

$\Rightarrow$ L'urètre est le canal qui conduit l'urine de la vessie vers l'extérieur;

$\Rightarrow$ Les organes pelviens, ce sont des organes qui sont dans la région du bassin;

$\Rightarrow$ Le sperme, est un liquide blanchâtre, légèrement collant, qui sert de milieu protecteur pour les spermatozoïdes. La quantité de sperme émise lors d'une éjaculation est d'environ 2 à $5 \mathrm{ml}$, chaque $\mathrm{ml}$ renfermant 50 à 130 millions de spermatozoïdes. 

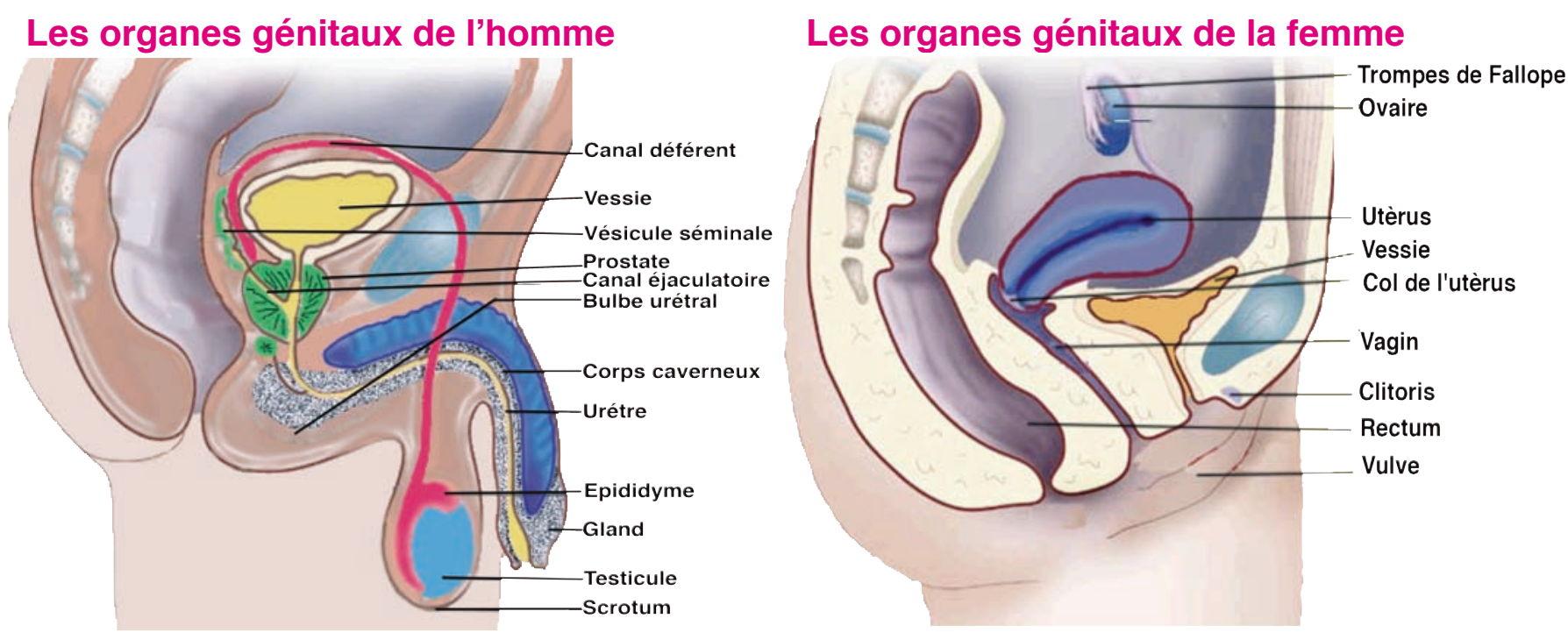

(1) Description des organes génitaux de la femme

L'appareil génital de la femme comporte les organes génitaux externes et les organes génitaux internes.

\section{Les organes génitaux externes:}

Contrairement à l'homme, les organes génitaux de la femme sont plus discrets et davantage dissimulés à l'intérieur du corps.

La vulve, est un ensemble complexe d'organes qui comprend: le mont de vénus, les grandes lèvres, les petites lèvres, le clitoris, le vestibule, les glandes de Bertholin et le périnée.

$\Rightarrow$ Le mont de Vénus correspond à un coussinet de tissu situé devant l'os pubien qui se recouvre à la puberté de poils pubiens;

$\Rightarrow$ Les grandes lèvres sont deux replis de peau recouverts de poils à partir de la puberté, bordant l'ouverture des conduits urinaire et vaginal. Généralement, elles sont accolées, laissant à peine entrevoir l'orifice vaginal ou laissant dépasser les petites lèvres;

$\Rightarrow$ Les petites lèvres sont deux replis cutanés de couleur rosacée, sans poils, se situant à l'intérieur des grandes lèvres;

$\Rightarrow$ Le clitoris est l'équivalent du gland du pénis chez la femme. C'est un petit organe qui peut atteindre jusqu'à un centimètre et qui procure le plus de plaisir sexuel à la femme. Il est situé à la jonction des petites lèvres et est recouvert d'un capuchon;

$\Rightarrow$ Le vestibule est une région limitée de chaque côté par les petites lèvres. Sur son fond, on retrouve deux ouvertures: vers l'avant, le méat urinaire qui permet l'évacuation de l'urine et vers l'arrière, l'orifice vaginal et immédiatement sous l'orifice vaginal, l'hymen qui vient fermer partiellement le vagin. C'est par la présence de l'hymen qu'on détermine la virginité chez la jeune fille (cependant, certaines filles naissent sans hymen);

$\Rightarrow$ Les glandes de Bartholin, au nombre de deux, sont situées de part et d'autre de l'orifice vaginal. Elles sécrètent quelques gouttes d'un liquide clair et muqueux qui sert à lubrifier la vulve lorsqu'il y a excitation sexuelle;

$\Rightarrow$ Le périnée est une région en forme de losange comprise entre les lèvres et l'anus. 


\section{Les organes génitaux internes:}

Le vagin, est un organe musculaire situé entre la vulve et le col de l'utérus. Le vagin sert à la pénétration lors des rapports sexuels. Il sert de passage au fœtus pendant l'accouchement et de passage des règles;

$\Rightarrow$ L'utérus (matrice) est un organe creux, en forme de poire renversée. Il est situé au-dessus de la vessie. Le fœus (bébé) se développe dans l'utérus. Le col est l'entrée de l'utérus;

$\Rightarrow$ Les trompes de fallope sont deux canaux, d'environ $10 \mathrm{~cm}$ de long, qui partent du fond de l'utérus pour se diriger vers chaque ovaire. C'est dans les trompes qu'a lieu la fécondation. Ces canaux permettent aux spermatozoïdes de l'homme d'arriver jusqu'à l'ovule de la femme. Les trompes sont aussi le lieu où l'on peut effectuer la stérilisation de la femme (ligature des trompes);

Les ovaires, au nombre de deux, sont situés de chaque côté de l'utérus. Ils ont pour fonction de produire les ovules et d'assurer leur maturation.

Les seins ne font pas partie du système génital. Cependant, ils ont un rôle à jouer dans la reproduction car ils sont les organes de lactation.

\section{Anatomie du sexe de la femme}

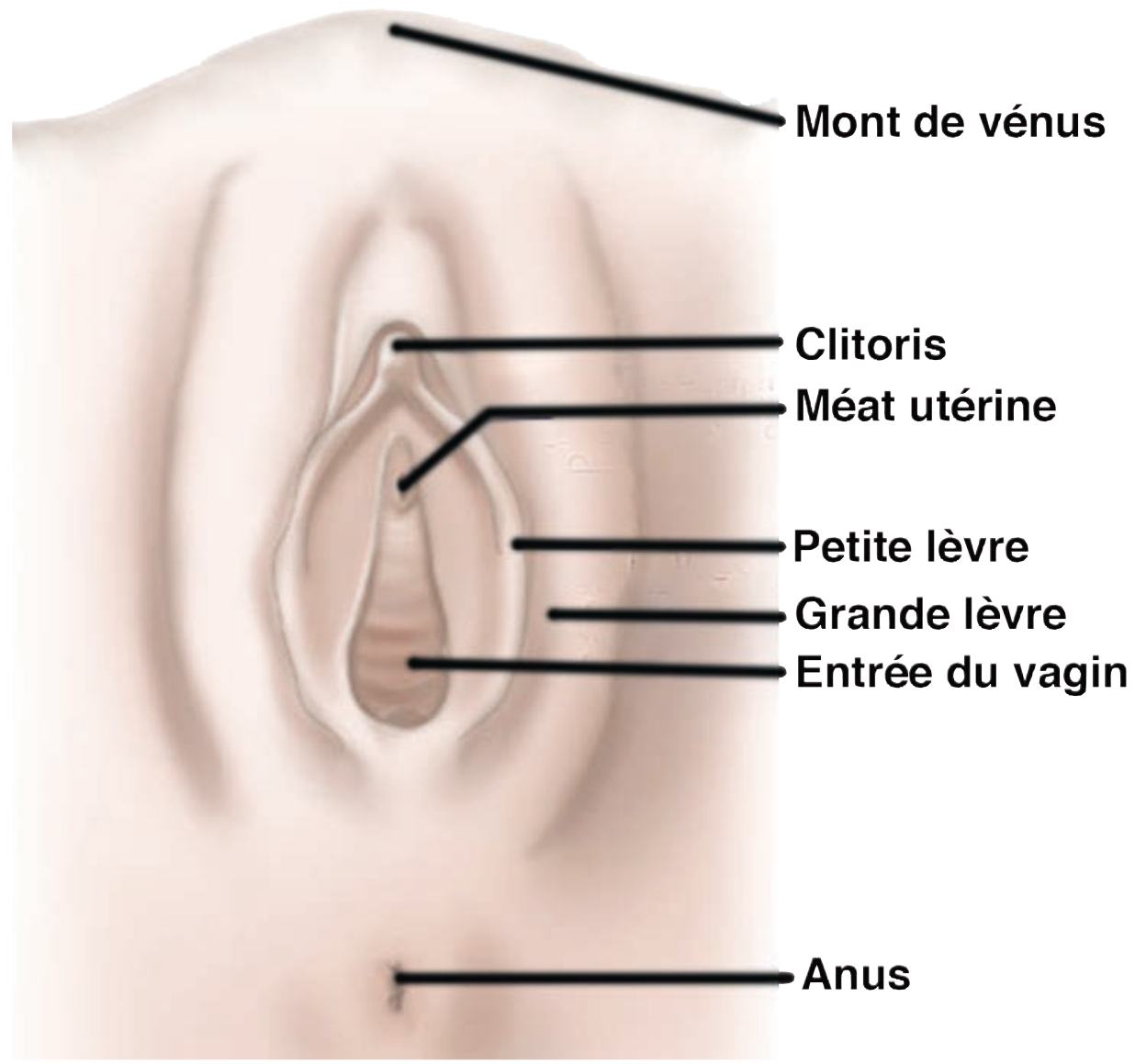




\section{Tabagisme, alcoolisme et toxicomanie}

L'adolescence est le temps des expériences: première cigarette, première ivresse, première drogue, première relation sexuelle...

Par goût du risque, des défis, par détresse ou par curiosité, les adolescents ont des penchants pour l'usage des substances qui peuvent être nocives pour eux. L'usage de la cigarette, l'alcool et la drogue peut affecter dangereusement la santé physique et mentale si aucune action de prévention ou de prise en charge n'est envisagée.

\section{Pourquoi les adolescents consomment les substances nocives}

Beaucoup de parents pensent que leur fils ou leur fille a cédé aux pressions de ses pairs. Les adolescents disent que s'ils décident de fumer, de boire de l'alcool ou de se droguer, c'est pour combattre l'ennui, se sentir mieux, oublier leurs problèmes et se détendre, avoir du plaisir, satisfaire leur curiosité, prendre des risques, calmer leur malaise, se sentir adulte, affirmer leur indépendance, appartenir à un groupe, ou pour être dans le vent.

Or beaucoup de personnes perdent le contrôle de leur consommation quand elles utilisent ces substances. Elles ne savent pas quelle quantité elles consomment, ni comment elles se comportent quand elles ont absorbé ces substances.

Quand l'esprit d'une personne ressent un fort besoin pour l'alcool, la drogue ou le tabac, on parle de dépendance. Quand c'est son corps qui ressent ce besoin et que la personne tombe malade si ce besoin n'est pas satisfait, on parle d'addiction.

Il faut inciter les adolescents à éviter l'usage de ces substances nocives. Le dialogue parents/adolescents et l'éducation par les pairs ont un rôle très important dans les comportements de consommation des adolescents.

Les adolescents doivent avoir des informations claires, précises et exactes sur ces substances, leurs conséquences, la manière dont elles affectent leur santé.

\section{Conséquences de l'utilisation des substances nocives}

Les risques associés à la consommation des substances nocives dépendent de la substance absorbée, la vulnérabilité du consommateur, la quantité consommée.

On distingue trois types de consommation: l'usage récréatif, l'abus et la dépendance.

() L'usage récréatif correspond à une consommation occasionnelle: l'adolescent fume pour faire comme les autres, il consomme la drogue par curiosité. Ce type de consommation peut ne pas entraîner de complications pour la santé, ni de troubles du comportement si cela s'arrête strictement au stade de l'expérimentation. Cependant il faut très tôt dissuader les jeunes de se lancer dans cette expérimentation en insistant sur les conséquences négatives de l'usage de ces substances et le risque de dépendance;

( ) L'abus: on parle d'abus quand la consommation commence à nuire à la santé physique et psychologique de l'individu ou de son entourage (exemple: comportements violents pendant l'ivresse, dégradations des relations familiales...). Le consommateur est dans l'incapacité de se passer du produit pendant quelques jours;

() La dépendance: l'utilisation prolongée d'une substance amène des modifications dans le cerveau qui créent le phénomène de dépendance. La vie quotidienne du consommateur tourne autour de la recherche du produit. Il lui devient très difficile de résister au besoin de consommer. Il y a une dépendance physique. L'organisme va réagir à l'absence du produit. C'est un état de manque qui s'accompagne de symptômes physiques incommodants (douleurs, démangeaisons, vomissements...). La dépendance psychologique correspond au souvenir du plaisir associé au tabac, à l'alcool, à la drogue et que la personne cherche à retrouver. 


\section{Principales substances nocives}

\section{Le tabac:}

La cigarette contient des substances toxiques (nicotine, goudron, dioxyde de carbone...) très dangereuses pour l'organisme. C'est pourquoi les paquets de cigarettes portent un avertissement pour la santé (n'est-ce pas insensé de payer pour un produit dont on vous informe qu'il est dangereux pour votre santé?).

La cigarette coûte cher et porte atteinte aux non-fumeurs en polluant l'atmosphère. Les méfaits du tabac sont:

(1) Des bourdonnements d'oreilles, des problèmes de circulation du sang. Ces phénomènes sont causés par la nicotine qui est également responsable de la plupart des maladies cardio-vasculaires chez les fumeurs;

(2) L'infection des poumons et le cancer de la bouche, de la gorge, des poumons... dûs au goudron;

() La réduction du volume d'oxygène dont l'organisme a besoin pour faire vivre les tissus;

(1) L'accélération des rides, le noircissement des dents, des lèvres et des doigts;

() Une mauvaise haleine et des habits qui empestent;

(1) Le gaspillage des ressources familiales dû à l'achat de tabac et les frais médicaux pour soigner les affections occasionnées par l'usage de ce produit.

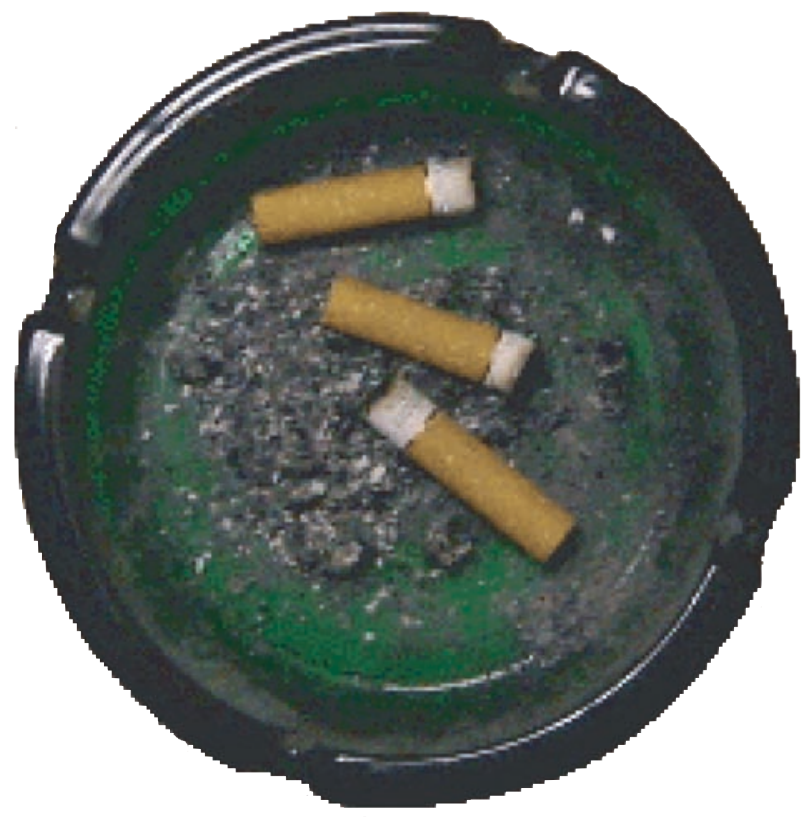

L’alcool:

L'alcool contient de l'éthanol et du méthanol (substance nocive et qui peut rendre aveugle). L'alcool bu passe directement dans le sang en quelques minutes. Son élimination par le foie dure plusieurs heures. En quelques minutes, le sang transporte l'alcool dans toutes les parties de l'organisme, y compris le cerveau. L'alcool a plusieurs effets sur les neurones de façon à diminuer leur activité. D'où l'effet sédatif de l'alcool.

La prise régulière d'alcool affecte la faculté de coordination. Les réactions du sujet sont lentes et sa faculté de discernement et de prise de décisions rapides diminue. L'individu qui consomme de l'alcool est plus exposé aux risques d'accidents que les autres. En outre, sous l'emprise de l'alcool, il peut être amené à faire des choses qu'il n'aurait jamais osé faire en étant lucide, l'ivresse l'ayant privé de son bon sens.

Par ailleurs, dans certains pays, beaucoup d'adolescentes ont eu leur premier rapport sexuel après avoir bu de l'alcool ou avoir été droguées. Il s'ensuit souvent une grossesse non désirée ou une IST...

Les adolescentes et/ou femmes enceintes doivent absolument éviter de boire de l'alcool pour ne pas mettre en danger leur bébé. L'absorption d'alcool durant la grossesse peut avoir des répercussions négatives sur le bébé: malformations du bébé, déficiences mentales...

L'abus d'alcool peut avoir comme conséquence des maladies graves comme la cirrhose (cancer du foie).

Au plan social, l'abus d'alcool est une des causes principales de dislocation de la cellule familiale.

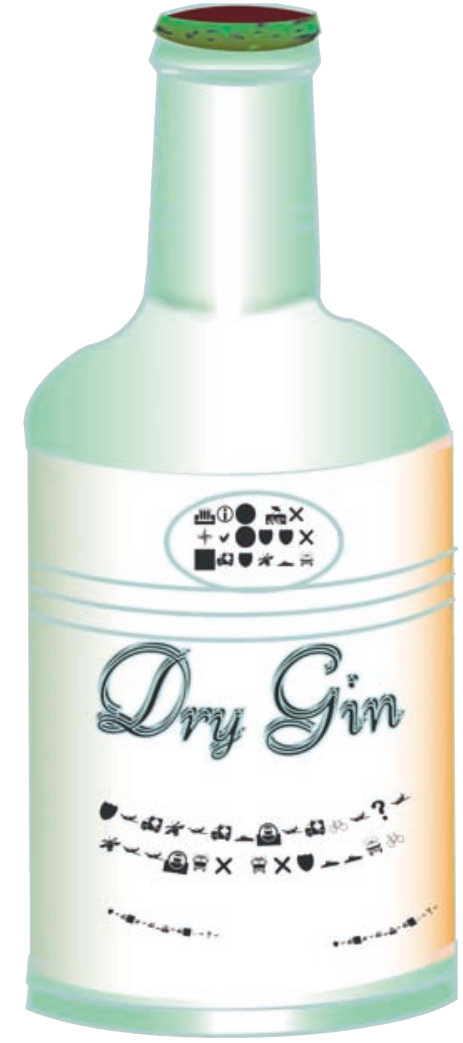




\section{Les drogues:}

Il existe plusieurs sortes de drogues. Toutes ont des conséquences plus ou moins néfastes pour la santé. Elles peuvent mener à des comportements à risque qui affectent gravement la santé. Les drogues agissent de façon artificielle sur le cerveau, particulièrement sur les neurones.

Certains rangent le café, le thé, la noix de cola parmi les drogues. Ces produits contiennent une substance appelée alcaloïde qui entraîne la dépendance. Il est très difficile à ceux qui absorbent ces produits, pendant longtemps, de s'en passer. Le sevrage brusque s'accompagne de maux de tête, de torpeur, de paresse. Certaines personnes deviennent très irritables.

Le cannabis encore appelé chanvre indien, marijuana ou herbe est une drogue qui est fumée ou mâchée (hashish). Il donne une sensation de paix à l'individu, le rend paresseux, jovial et amical. Son abus diminue la concentration et peut ainsi entraîner des accidents. Chez certains individus, son utilisation prolongée peut causer des troubles mentaux. Le cannabis a des effets hallucinogènes: la personne croit voir ou entendre des choses qui n'existent pas en réalité. Sa consommation est un délit réprimé par la loi. La personne risque des peines d'amende et de prison.

Un autre type de drogue apprécié des jeunes est constitué de solvants, de l'essence (guinz), etc. Ces produits sont souvent utilisés par les jeunes de la rue. L'inhalation de l'essence, du solvant, de la colle... crée chez le sujet une sensation de bien être et de plénitude. La dépendance à ces produits est rapide et très forte. Ces substances inhalées sont toxiques et portent atteinte à la vue, au cerveau, aux poumons... Les jeunes qui utilisent ces produits ont souvent des comportements violents. Ils sont privés de discernement et par conséquent n'ont aucun sens des risques qu'ils encourent. Ce qui les expose à des accidents et des traumatismes graves.

Les "pilules" recouvrent l'ensemble des médicaments détournés de leur utilisation normale pour être utilisés comme des drogues. Certains ralentissent le rythme du cœur et la respiration... Le sujet est paresseux et déprimé. D'autres accélèrent le rythme cardiaque et la respiration. L'individu a des insomnies, il est souvent irrité et euphorique. Il est dans un état d'excitation continue.

Dans les "drogues dures" on classe l'hérö̈ne, la cocaïne, le LSD (lysergic acide dyethylamide), le crack... La fabrication, la vente et l'usage de ces produits sont formellement interdits dans tous les pays du monde. Ces drogues créent une situation de dépendance rapide et très forte. L'individu ne peut plus s'en passer et est prêt à tout pour se procurer sa "dose". Leurs effets sont variés. La cocaïne et le crack ont un effet stimulant très fort, tandis que l'héroïne est un puissant dépressif. La LSD est hallucinogène et crée des troubles mentaux. L'utilisation de ces substances est très dangereuse et débouche à long terme sur la mort. Le risque de contamination par le VIH par la pratique d'échange de seringues aggrave les conséquences néfastes de la consommation de drogues dures. 


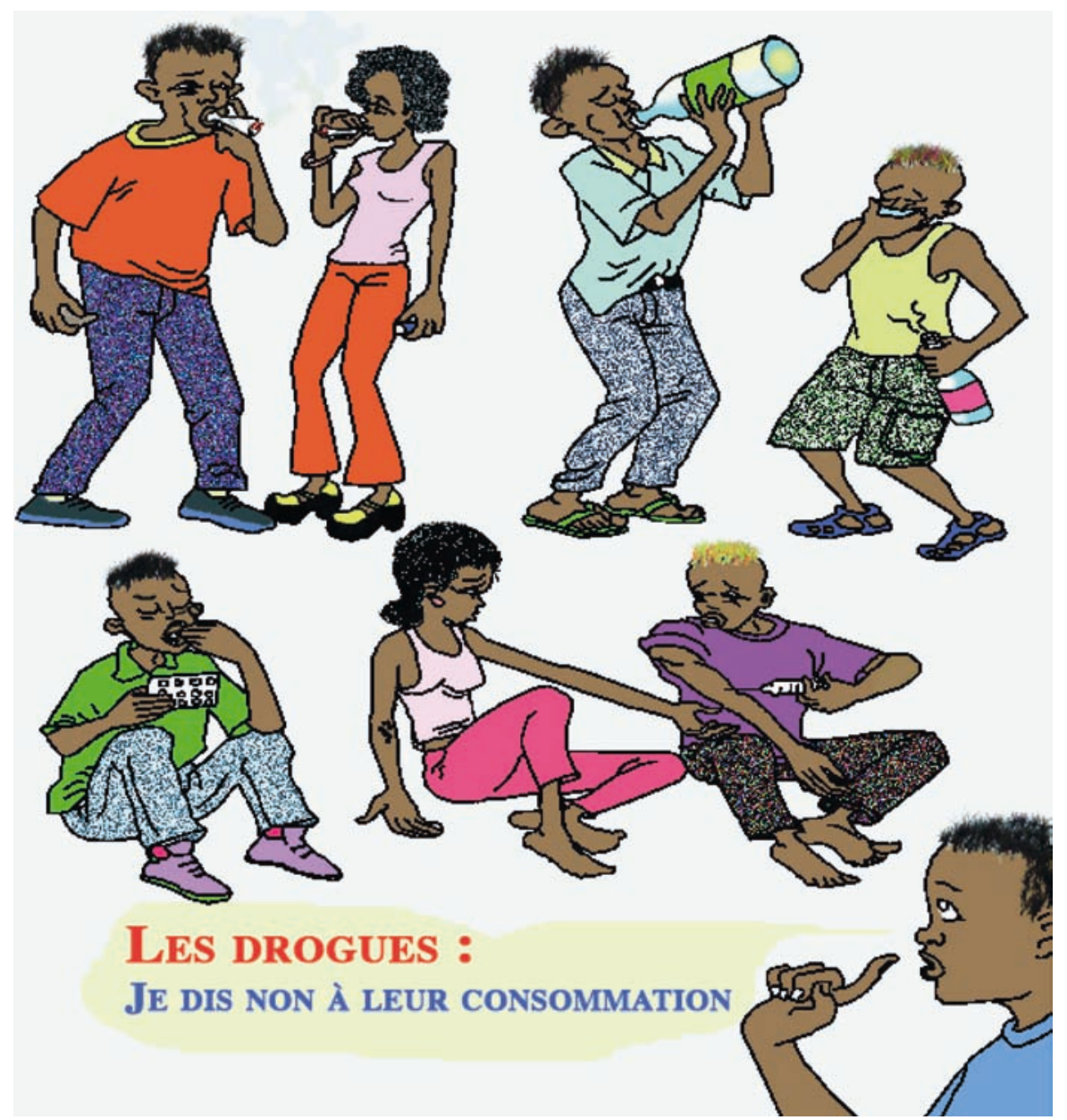

QUELQUES TUYAUX POUR EVITER AUX JEUNES DE S'ADONNER AU TABAC, A L'ALCOOL ET A LA DROGUE

\section{Pour les jeunes qui n'ont aucune expérience de ces produits, il faut:}

(1) Leur expliquer qu'aucun de ces produits n'est nécessaire à l'organisme;

(.) Leur demander de peser les avantages et les inconvénients qu'entraîne l'usage de ces produits;

(1) Leur apprendre à prendre une bonne décision;

() Leur apprendre à dire "NON";

( ) Les informer qu'ils doivent respecter les valeurs de leur société et leur religion et se soumettre volontairement aux lois édictées par la société;

(.) Leur apprendre à vivre en plein air et à faire de l'exercice physique;

() Leur recommander de ne pas fréquenter de copains qui fument, boivent ou se droguent.

\section{Pour les jeunes qui s'adonnent déjà au tabac, à l'alcool ou à la drogue, il faut:}

(.) Leur faire admettre qu'ils ont un problème, mais qu'ils ne sont pas un problème;

(.) Leur faire admettre qu'ils doivent agir aujourd'hui et non demain;

(.) Les inciter à arrêter tout de suite ou à diminuer progressivement leur consommation pour ensuite arrêter;

() S'ils recommencent, ne pas les blâmer et les encourager à arrêter de nouveau.

Certains individus peuvent tomber malade quelques jours s'ils arrêtent de fumer, de boire de l'alcool ou de se droguer. Ils sont agités ou déprimés, ils ont des douleurs, ils vomissent. Ils souffrent de troubles digestifs et du sommeil. Généralement, ces signes disparaissent au bout de quelques jours. L'exercice physique modéré jumelé à la vie en plein air peut aider à surmonter ces troubles. Si ces derniers persistent et que l'individu est de plus en plus mal en point, il faut l'amener chez un agent de santé. 


\section{Sexe et sexualité}

La puberté n'est pas très facile à vivre aussi bien pour les adolescents que pour leurs parents. Pour les adolescents, c'est la période des questionnements sur leur corps et d'expérimentation de leur sexualité. Les parents veulent que leurs enfants respectent les normes et les valeurs sociales établies. Il faut préparer adolescents et parents à gérer de façon positive cette période transitoire très critique pour l'épanouissement de l'enfant.

\section{Définitions:}

La sexualité: c'est l'ensemble de nos attitudes et comportements par rapport au sexe. Au-delà des aspects physiques, physiologiques, la sexualité concerne les aspects émotionnels, psychologiques et culturels liés au sexe. La sexualité d'un individu comprend son identité sexuelle et son orientation psychologique. La sexualité n'est donc pas exclusivement les rapports sexuels, c'est plutôt la combinaison d'un certain nombre de facteurs physiologiques et psychiques.

Le sexe relève de la biologie, de l'anatomie, de la physiologie. Le terme sexe se rapporte plus spécialement au système de reproduction et aux activités sexuelles de l'homme ou de la femme. C'est un élément fondamental de notre sexualité. Le sexe est le symbole de l'identité, de "la nature", de la personnalité de l'individu, de l'estime de soi.

Les termes "masculin" et "féminin" relèvent proprement du sexe. "Virilité" et "féminité" relèvent de la sexualité.

\begin{tabular}{|l|l|}
\hline $\begin{array}{l}\text { Sexe } \\
\text { au physique: masculin/féminin } \\
\text { à la biologie, la physiologie }\end{array}$ & $\begin{array}{l}\text { Sexualité } \\
\text { Se rapporte: }\end{array}$ \\
\hline $\begin{array}{l}\text { Appareils de reproduction masculin et féminin } \\
\text { au physique et } \\
\text { au psychologique }\end{array}$ \\
\hline $\begin{array}{l}\text { Exemple: } \\
\text { la femme est capable d'allaiter et } \\
\text { l'homme produit des spermatozoïdes }\end{array}$ & $\begin{array}{l}\text { Dépassant la physiologique, la biologie, la sexualité } \\
\text { embrasse les aspects émotionnels, psychologiques et } \\
\text { culturels de l'être }\end{array}$ \\
\hline
\end{tabular}

\section{Quelques préoccupations sur les changements physiques et physiologiques au cours de l'adolescence}

Les changements du corps constituent au début une source véritable d'inquiétude chez les adolescents. L'apparition des poils du pubis, des aisselles peuvent entraîner de l'angoisse, de la gêne chez l'adolescent. Mais ce sont surtout l'apparition des premières règles et premières éjaculations qui entraînent des interrogations et de l'angoisse chez les garçons et les filles.

Les premières règles: sont vécues comme une anormalité par la fille. Il lui est difficile d'en parler à ses proches parce qu'elle se sent gênée. La vue du sang qui évoque la plaie, la douleur peuvent faire croire à la fille qu'elle est malade. C'est pourquoi il est important de préparer la fille bien avant l'apparition des premières règles en lui expliquant que les règles ne sont pas du sang (même si elles contiennent des éléments sanguins) et qu'elles sont un événement normal dans le développement de la fille. Les règles ne sont pas seulement un signe de la capacité de tomber enceinte, mais une preuve de leur maturité féminine. 
En fonction de l'âge de la fille, il est important de l'informer sur le fonctionnent des règles, les douleurs éventuels, ainsi que les précautions hygiéniques (utilisation de linges propres) et comportementales. On doit dire à l'adolescente qu'elle peut tomber enceinte dès le premier rapport sexuel non protégé, l'informer sur la période de fécondité, sur la nécessité de l'utilisation des moyens de protection et de contraception...

Les premières éjaculations: la plupart des garçons connaissent l'existence des érections matinales et nocturnes. Ils sont souvent surpris par les premières éjaculations surtout qu'elles surviennent de façon inopinée. Ils éprouvent un malaise en pensant à la réaction de leur mère ou de leur entourage à la vue de ces tâches sur le drap. Souvent ce sont les conversations avec les amis, copains qui atténueront ce sentiment de malaise. Comme pour les filles, cette étape de la puberté doit être bien expliquée aux garçons afin qu'ils puissent la vivre avec moins d'angoisse. C'est aussi le moment d'attirer leur attention sur les risques d'une sexualité non protégée.

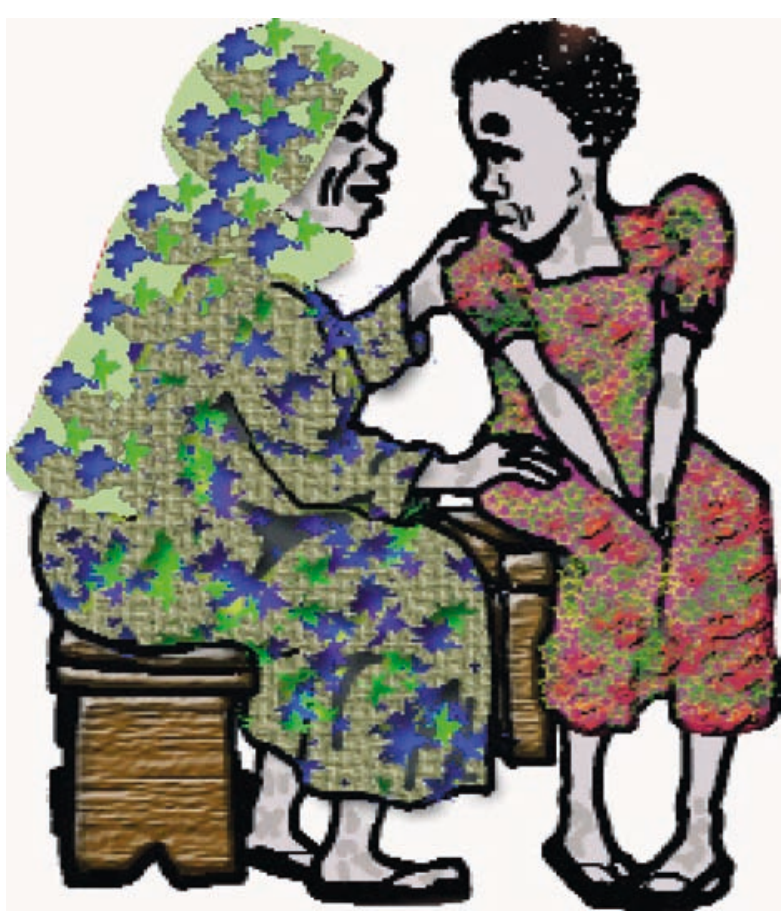

\section{Quelques comportements sexuels au cours de l'adolescence}

(1) La masturbation: La masturbation est la stimulation manuelle des organes génitaux sur soi ou sur son partenaire. Elle consiste à caresser les parties génitales. Elle peut commencer dès le bas âge avec les manipulations sexuelles (on peut voir des érections chez le petit garçon lors de contact du pénis avec la main). Cette pratique est observée aussi bien chez les garçons et chez les filles. La masturbation est une activité sexuelle qui pose un certain nombre de questionnements. Pour certains, elle constitue aussi bien un danger physique, psychique que moral. La masturbation chez l'adolescent est naturelle. C'est un comportement sexuel transitoire qui tend à disparaître avec les premiers rapports sexuels. Cependant, on peut observer cette pratique à l'âge adulte, ce qui s'explique souvent par un manque de partenaire ou une insatisfaction sexuelle.

\section{Mythes et réalités sur la masturbation}

\begin{tabular}{|l|l|l|}
\hline Mythe & \multicolumn{2}{|l|}{ Réalité } \\
\hline $\begin{array}{l}\text { Quelqu'un qui se masturbe } \\
\text { beaucoup devient un obsédé } \\
\text { sexuel }\end{array}$ & Faux & $\begin{array}{l}\text { La masturbation n'entrâne pas l'obsession sexuelle. C'est une } \\
\text { pratique courante chez l'individu qui aborde la puberté et qui a } \\
\text { tendance à s'estomper avec l'âge. }\end{array}$ \\
\hline $\begin{array}{l}\text { La masturbation distrait } \\
\text { l'individu de l'école ou de son } \\
\text { travail }\end{array}$ & Faux & $\begin{array}{l}\text { Cependant, comme le rappelle l'adage: “tout excès est nuisible”. } \\
\text { Si la masturbation permet de temps en temps de se libérer de } \\
\text { la tension sexuelle, elle ne doit pas être pratiquée de façon } \\
\text { excessive. }\end{array}$ \\
\hline $\begin{array}{l}\text { La masturbation empêche d'avoir } \\
\text { une relation sexuelle avec une } \\
\text { personne de sexe opposé }\end{array}$ & Faux & $\begin{array}{l}\text { La masturbation n'empêche en rien un individu d'avoir un } \\
\text { rapport sexuel avec une autre personne. }\end{array}$ \\
\hline Seul les hommes se masturbent & Faux & $\begin{array}{l}\text { Aussi bien les hommes que les femmes pratiquent la } \\
\text { masturbation }\end{array}$ \\
\hline La masturbation rend fou & Faux & $\begin{array}{l}\text { La masturbation en elle-même n'a aucune conséquence sur la } \\
\text { santé mentale }\end{array}$ \\
\hline
\end{tabular}


Les rapports hétérosexuels: l'adolescence est surtout la période de l'attirance vers l'autre sexe. On cherche à découvrir le sexe opposé. C'est la recherche du copain ou de la copine. Les adolescents disent qu'ils ont des rapports sexuels par curiosité, par amour, à cause de la pression des pairs et de certains adultes, des besoins financiers... Cependant les adolescents sont souvent mal informés sur les risques éventuels liés à cette activité sexuelle. Les problèmes d'accès aux services de santé les exposent aux Infections Sexuellement Transmissibles (IST), au VIH/SIDA et aux grossesses précoces;

(2) Autres comportements sexuels transitoires: il s'agit souvent de jeux sexuels qui permettent aux adolescents de découvrir leur corps, la sexualité et le plaisir tels que les baisers, les caresses... On peut noter également la sexualité de groupe qui est cependant rare.

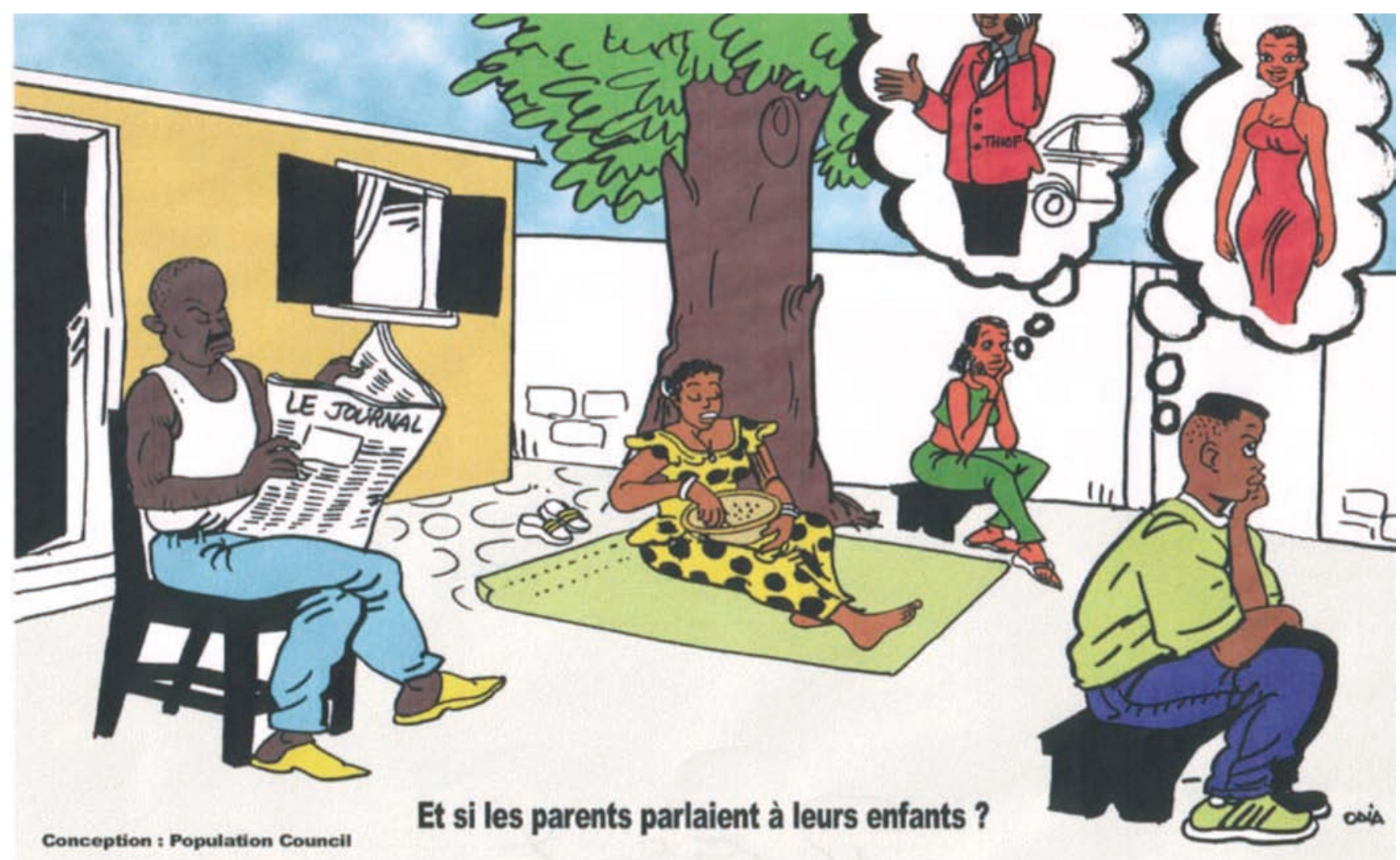

Il est important de préparer les adolescents à une vie adulte harmonieuse et maîtrisée en leur offrant une éducation sexuelle adéquate. L'abstinence avant le mariage et l'intérêt de différer le premier rapport sexuel doivent être mis en exergue. 


\section{La grossesse}

C'est la période de la gestation chez la femme, de la conception à la naissance du bébé. Elle dure 9 mois et comporte les étapes suivantes:

(1) La fécondation: rencontre et fusion de l'ovule et du spermatozoïde;

() La segmentation: premières divisions cellulaires;

(1) La nidation;

(1) Le développement embryonnaire;

(.) Le développement fœtal;

() L'accouchement.

\section{Etapes de la grossesse}

\section{Fécondation}

Après un rapport sexuel, des millions de spermatozoïdes nagent dans le vagin. Ils peuvent vivre pendant trois jours à l'intérieur du corps. Quelques-uns parviennent à entrer dans l'utérus et pénètrent ensuite dans les trompes de Fallope. Un seul spermatozoïde va fusionner avec l'ovule: c'est la fécondation ou la formation d'un œuf par la fusion d'un ovule avec un spermatozoïde.

Les spermatozoïdes peuvent aussi pénétrer dans le vagin s'ils sont éjaculés tout près de l'ouverture du vagin, et la femme peut devenir enceinte sans pénétration.

S'il n'y a pas d'œuf mûr relâché au moment des rapports sexuels, la femme ne pourra pas être enceinte.

\section{Segmentation ou début de division cellulaire}

Une fois que l'ovule a été fécondé, aucun spermatozoïde ne peut y pénétrer. L'œuf fécondé commence à se diviser et à grandir: c'est la segmentation qui correspond à la succession des divisions cellulaires. L'œuf se divise d'abord en deux, puis en quatre, en huit, en seize cellules.

\section{Nidation et début de croissance}

L'œuf fécondé continue alors son chemin jusqu'à l'utérus où il s'attache dans la muqueuse utérine: c'est la nidation ou implantation. Elle se produit 7 à 8 jours après la fécondation. La muqueuse utérine n'est plus éliminée tous les mois, donc la femme enceinte ne voit plus ses règles. L'arrêt de la menstruation est d'habitude le premier signe de la grossesse.

Si les conditions dans l'utérus sont favorables pour sa croissance et si l'ovule et le spermatozoïde sont sains, c'est le début du développement du bébé.

Si le corps ne peut pas fournir assez de nourriture, ce nouvel organisme, à l'intérieur, ne peut pas grandir comme il faut. Il est donc très important que la femme enceinte mange des quantités suffisantes et une très grande variété d'aliments pour avoir un corps en bonne santé et pour supporter la grossesse sans dommage pour elle-même et pour le fœetus qui se développe.

\section{Développement de l'embryon}

Pendant les trois premiers mois de la grossesse, le bébé qui est en train de se développer est appelé embryon. Ce premier trimestre est donc la période embryonnaire. Le bébé grandit à l'intérieur de l'utérus dont il tire sa nourriture. A la fin de la période embryonnaire, les ébauches de tous les principaux organes adultes sont présentes. 
Trois membranes embryonnaires protègent et nourrissent l'embryon:

(1) L'amnios qui se remplit de liquide protégeant le bébé contre les chocs;

(1) Le chorion qui est la partie embryonnaire du placenta;

(1) L'allantoïde qui permet les échanges entre la mère et le bébé.

Un embryon de neuf semaines est encore si petit qu'il ne recouvre q'une petite partie de la paume de la main. Il faut environ trois mois pour que l'embryon se forme à l'intérieur de son sac protecteur. La tête et la colonne vertébrale se développent d'abord. Il ne pèse que 69 grammes à la fin du troisième mois. On peut remarquer les oreilles, les yeux et le nez à quatre mois.

Le placenta est tout à fait développé vers le troisième mois. Il devient la principale source de nourriture du futur bébé pendant la grossesse. Le cordon ombilical relie le ventre de l'embryon au placenta. C'est par le cordon ombilical que l'embryon reçoit du placenta ce dont il a besoin pour grandir. Le placenta, à son tour, le reçoit de la mère. Le cordon est la "Ligne de vie" du bébé. La nourriture, l'oxygène et aussi les déchets passent par le cordon ombilical.

La femme enceinte peut se livrer à ses activités habituelles sans se faire de mal pendant la grossesse. Faire de l'exercice est bon pour elle, sauf si elle a des problèmes spéciaux. Mais elle a besoin de plus de repos et de plus de sommeil. Elle peut se sentir spécialement fatiguée pendant les premiers mois. L'alimentation de la femme enceinte doit être équilibrée avec des aliments nutritifs: les trois premiers mois établissent la base pour avoir un bébé bien portant. Certaines femmes ont la nausée le matin durant cette période. En cas de vomissements importants, la femme doit chercher de l'assistance professionnelle.

Une fausse couche (qui signifie que l'embryon est expulsé spontanément) arrive le plus souvent pendant les trois premiers mois de la grossesse, si l'embryon n'est pas normal ou s'il ne grandit pas. Les trois premiers mois sont aussi la période la plus probable pour un avortement.

Après une fausse-couche, il est important que tout ce qui avait grandi dans l'utérus sorte sinon, une infection pourrait arriver. Il faut aller à un point de prestation de santé ou voir un médecin et se faire examiner.

\section{Développement de la grossesse ou développement fœtal}

Il se déroule du troisième mois jusqu'à l'accouchement. Le bébé est alors appelé fœtus, d'où le terme de développement fœtal. Au cours de cette période, le fœtus prend une apparence humaine.

A environ quatre (4) mois, on commence à sentir la vie. Tout d'abord, on sent à peine le mouvement du fœetus, puis il devient plus fort et on le sent remuer. Certains fotus remuent beaucoup et sont très actifs à l'intérieur de leur sac rempli de fluide amniotique

Ce n'est qu'après quatre mois (parfois plus pour un premier bébé) que la grossesse commence à se voir. L'embryon remue librement, protégé par le liquide amniotique qui joue le rôle d'un coussin et maintient une température constante. L'embryon continue à être nourri par le placenta à travers le cordon ombilical jusqu'à la naissance du bébé. Le placenta est habituellement expulsé quelques minutes après le bébé.

Le sexe du futur bébé est déterminé au moment de la fécondation par le spermatozoïde de l'homme. Tous les embryons, masculins ou féminins, se ressemblent pendant les huit premières semaines. Après huit semaines, les organes sexuels distinctifs masculins ou féminins commencent à se former.

\section{La parturition ou l'accouchement}

La parturition, communément appelée l'accouchement, est la naissance du bébé. Elle survient généralement 280 jours après les dernières règles. Les évènements qui mènent à l'expulsion du foetus constituent le travail. Stimulé par des hormones secrétées par le fœtus et le placenta, l'utérus se contracte. Ces contractions expulsent à l'extérieur des voies génitales le fotus puis le placenta. C'est la délivrance. 


\section{Les changements du corps pendant la grossesse}

Les changements du corps de la femme enceinte sont à peine visibles pendant la première moitié de la grossesse. La plupart d'entre eux ont lieu à l'intérieur du corps. Le premier changement, au début de la grossesse est l'arrêt de la menstruation. Quand les règles sont en retard de deux ou trois semaines, la femme fait un test à l'hôpital ou à la clinique, pour s'assurer qu'elle est enceinte ou pas. Si la grossesse ne peut pas continuer, le meilleur moment pour avoir un avortement est le plus tôt possible, ou avant trois mois.

Pendant les trois derniers mois, le ventre grossit très rapidement, parce que le foetus prend beaucoup de poids à la fin de la grossesse. L'utérus s'agrandit parce qu'il contient le fœetus qui grossit rapidement, ce qui fait bomber le ventre. Il pousse sur les autres organes internes, y compris la vessie; c'est pourquoi la femme a besoin d'uriner plus fréquemment. Il presse aussi sur les poumons et la femme peut avoir le souffle court. Pendant les derniers mois précédant la naissance du bébé, le fœtus remplit presque tout le ventre.

Les seins et les bouts des seins grossissent. Ils se préparent à produire le lait qui nourrira le bébé après sa naissance. Les glandes lactées, qui produisent le lait, grossissent. Les bouts des seins s'élargissent aussi et brunissent.

Pour déterminer le jour probable de la naissance du bébé, il faut prendre le premier jour des dernières règles, déduire trois mois, puis ajouter un an et sept jours. Par exemple: si la femme a ses dernières règles le huit (8) janvier, on peut s'attendre à ce qu'elle accouche vers le milieu du mois d'octobre. La grossesse dure environ deux cent quatre vingt (280) jours ou quarante (40) semaines à partir de la dernière menstruation, mais il y a beaucoup de variations normales.

Le corps de la femme est fait de telle sorte que la structure des os du bassin permet à la tête du bébé de sortir sans être endommagée. Pour être sûre que le bassin est assez grand pour permettre un accouchement normal, il faut faire mesurer d'avance le bassin dans une maternité.

Le contrôle prénatal régulier est important pour vérifier le développement du bébé. Le progrès de la grossesse doit être contrôlé régulièrement afin d'éviter des problèmes inattendus au moment de l'accouchement.
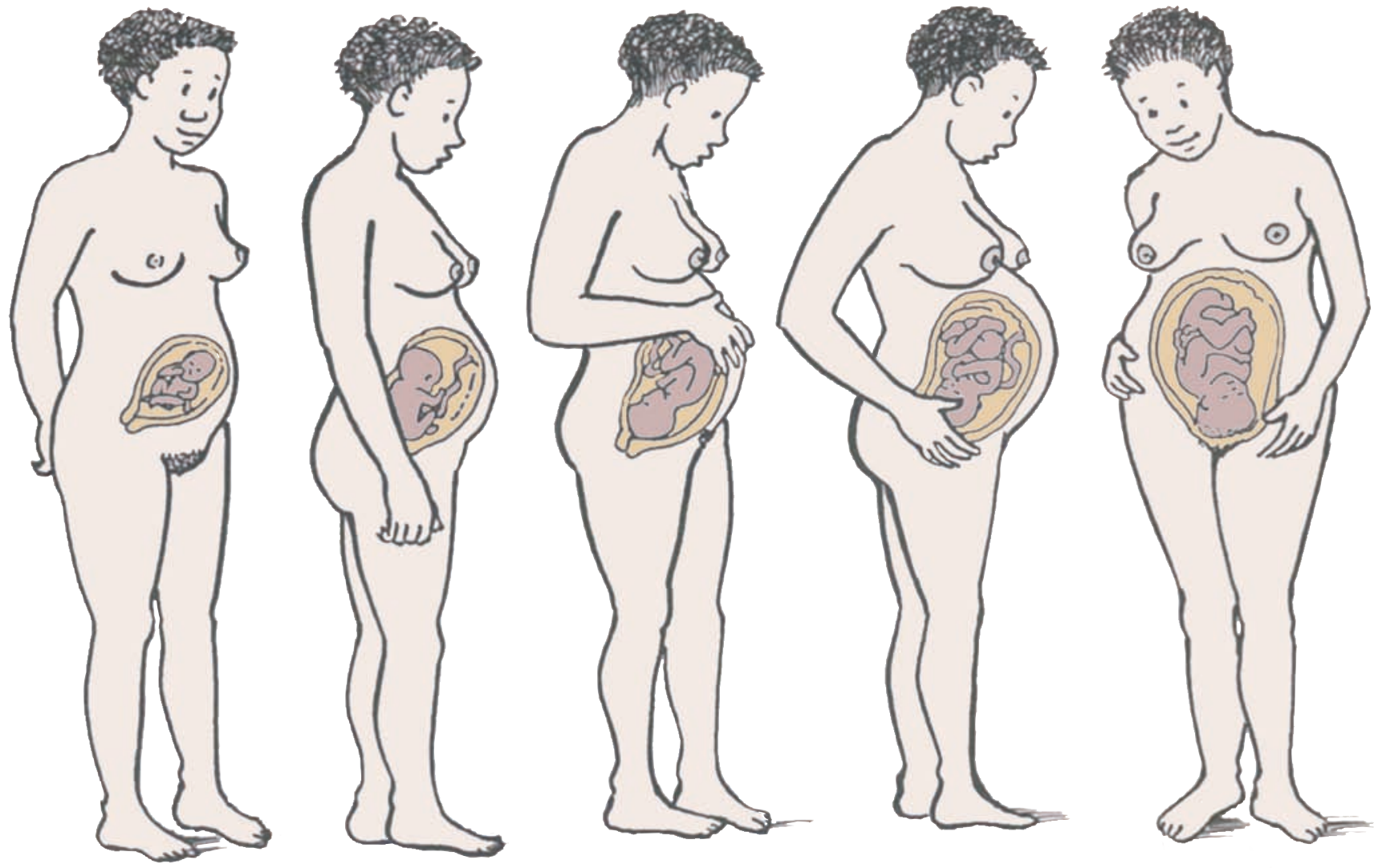


\section{Les méthodes contraceptives}

La contraception désigne l'ensemble des méthodes utilisées pour éviter une grossesse. En l'absence de contraception, une fécondation est possible dès la première relation sexuelle.

\section{Quelques messages cles:}

$\Rightarrow$ L'abstinence est l'unique méthode qui permet à la fois de se prémunir d'une grossesse indésirable et/ou d'une Infection Sexuellement Transmissible (IST) et dont l'efficacité est de 100\%;

$\Rightarrow$ Il n'y a aucune raison médicale qui justifie que l'on refuse quelque méthode contraceptive que ce soit pour une question d'âge seulement. Mais les considérations non médicales (risque d'IST, communication entre partenaires, etc....) sont très importantes aussi;

$\Rightarrow$ Les adolescents qui ne peuvent s'empêcher d'avoir une relation sexuelle doivent choisir la méthode la mieux adaptée à leur situation;

$\Rightarrow$ Il n'y a pas de bonne ou de mauvaise méthode contraceptive. Celle qui marche bien pour une personne, peut ne pas marcher pour l'autre. Chaque individu doit choisir la méthode qui lui convient le mieux;

$\Rightarrow$ Pour leur permettre de choisir en toute connaissance de cause, il faut donner aux jeunes des informations sur la disponibilité des produits contraceptifs, leur mode d'emploi, leurs avantages et inconvénients, leurs coûts...

\section{Les principales methodes contraceptives}

\section{Abstinence:}

C'est le fait de s'interdire volontairement un rapport sexuel. Par rapport au contexte culturel et religieux, cette approche est la mieux indiquée pour les adolescent(e)s qui ne sont pas encore marié(e)s. Elle a l'avantage d'empêcher les grossesses non désirées et les IST. L'abstinence requiert un engagement ferme, une grande motivation et une parfaite maîtrise de soi. Elle peut être très difficile à faire accepter aux jeunes, mais pas impossible.

L'abstinence sexuelle avant le mariage est surtout une valeur très forte dans les sociétés où les relations sexuelles hors mariage sont interdites. Elle est très fortement recommandée chez les adolescents.

\section{Les méthodes naturelles:}

La planification familiale naturelle comprend une variété de méthodes. Toutes nécessitent que la femme surveille les phases de son cycle et connaisse les jours de chaque cycle durant lesquels un ovule pourrait être fécondé. Par conséquent il faut éviter d'avoir un rapport sexuel durant toute la période féconde.

Selon la méthode de planification familiale naturelle choisie, la femme doit noter les dates de ses règles, les changements de température et l'humidité cervicale, et tout indice physiologique susceptible de l'informer qu'il y a ovulation ou non.

ATTENTION: les méthodes naturelles ne sont pas adaptées pour les adolescents: les adolescentes ont des cycles très irréguliers; ces méthodes ne protègent pas des IST dont l'infection à VIH/SIDA.

\section{(.) La méthode du calendrier ou méthode du rythme ou méthode Ogino}

Consiste à compter le nombre de jours pour identifier le début et la fin de la période féconde. On détermine la phase fertile du cycle menstruel en observant au minimum la durée des six (6) cycles précédents. La méthode du calendrier ne suffit pas à elle seule, surtout lorsque la femme a un cycle irrégulier.

\section{La méthode thermique ou méthode de température basale du corps}

Elle est basée sur la courbe de température du corps au repos, c'est à dire la température basale. La température du corps de la femme au repos augmente légèrement au moment de l'ovulation. La femme prend sa température basale chaque matin au lever et l'inscrit avec soin sur une feuille, cette prise de température permet de déterminer dans le cycle menstruel la période d'ovulation et la période infertile. 


\section{La méthode de la glaire cervicale ou méthode d'auto observation ou méthode Billings}

La femme détermine les jours où elle est non fertile et les jours où elle est fertile en observant quotidiennement les changements de l'aspect de sa glaire. Pour éviter la grossesse, il faut s'abstenir de tout rapport sexuel pendant la période fertile.

\section{- La méthode de l'allaitement maternel et de l'aménorrhée (MAMA)}

Si elle allaite son enfant exclusivement au sein et à la demande du bébé, la femme qui vient d'accoucher n'a pas de retour des règles jusqu'à six (6) mois après son accouchement, elle a donc très peu de risques de tomber enceinte.

\section{Le coït interrompu ou retrait}

C'est un rapport sexuel au cours duquel le pénis est volontairement retiré du vagin de sorte que l'éjaculation se produit en dehors du vagin.

\section{Comment ces méthodes empêchent-elles la grossesse?}

La planification familiale naturelle permet aux couples de connaître la période de fécondité de la femme afin d'éviter d'avoir des relations sexuelles durant toute cette période. Ces méthodes peuvent être combinées à d'autres méthodes utilisées occasionnellement durant la période de fécondité (par exemple le préservatif).

\section{Quels sont les avantages de ces méthodes?}

$\Rightarrow$ Bien maîtrisées, ces méthodes peuvent aider les couples à avoir ou à éviter une grossesse selon leur souhait;

$\Rightarrow$ Elles n'ont aucun effet secondaire;

$\Rightarrow$ Elles ne coûtent rien;

$\Rightarrow$ Elles sont réversibles (on peut arrêter quand on veut);

$\Rightarrow$ Elles permettent au couple et particulièrement à la femme de connaître son corps;

$\Rightarrow$ Elles sont acceptées par la religion;

$\Rightarrow$ Elles font participer les hommes au planning familial.

\section{Quels en sont les inconvénients et/ou effets secondaires?}

Moins efficaces que les autres méthodes;

Demandent la coopération et l'engagement du couple;

$\Rightarrow$ Très compliquées pour toute femme ayant un cycle menstruel irrégulier et chez les adolescentes qui sont en début de menstruations;

$\Rightarrow$ Nécessitent du temps et de la patience pour l'apprentissage;

$\Rightarrow$ Certaines méthodes naturelles demandent un niveau minimum d'alphabétisation;

$\Rightarrow$ Certaines femmes peuvent être déréglées à cause de paramètres imprévus tels que: une poussée de fièvre, une infection vaginale, une forte émotion...

$\Rightarrow$ Demandent une surveillance quotidienne et beaucoup d'attention sur les changements qui surviennent dans l'organisme;

$\Rightarrow$ Ne procurent absolument aucune protection contre les IST/SIDA.

\section{Quel est le mode d'emploi?}

$\Rightarrow$ Le mode d'emploi repose sur la détermination exacte de la période d'ovulation et de la période de fertilité, afin d'éviter les rapports sexuels durant cette phase ou alors de prévenir la grossesse par d'autres moyens.

\section{Qui peut utiliser la méthode?}

N'importe quelle femme ayant commencé à avoir ses règles, particulièrement celles qui ont un cycle régulier;

Toute femme assez motivée pour connaître son corps. 


\section{Les methodes barrieres}

\section{Le condom:}

Le condom appelé aussi préservatif ou capote est une enveloppe en caoutchouc mince conçue pour recouvrir le pénis en érection. Il existe un préservatif conçu spécialement pour la femme que l'on place dans le vagin lors du rapport sexuel.

\section{Comment l'utilisation des condoms empêche-t-elle la grossesse?}

$\Rightarrow$ Aussi bien le préservatif masculin que le préservatif féminin empêchent les spermatozoïdes de pénétrer dans le vagin pour aller féconder l'ovule en créant une barrière physique entre les spermatozoïdes et l'ovule.

$\Rightarrow$ La plupart des condoms sont enduits d'un lubrifiant auquel certains sont parfois ajoutés des agents antimicrobiens et un spermicide (qui tue les spermatozoïdes) pour renforcer leur efficacité.

\section{Quels sont les avantages du préservatif?}

$\Rightarrow$ Facile à se procurer et à utiliser après une simple démonstration;

$\Rightarrow$ Pas d'effets secondaires (sauf dans de rares cas d'allergie au latex);

$\Rightarrow$ Disponible sans ordonnance, ni visite médicale;

$\Rightarrow$ Double protection: empêche les grossesses non désirées et les IST/ SIDA s'il est utilisé correctement;

$\Rightarrow$ Bon marché et convient à ceux qui ont des rapports occasionnels comme les adolescent(e)s.

\section{Quels sont les inconvénients et/ou effets secondaires?}

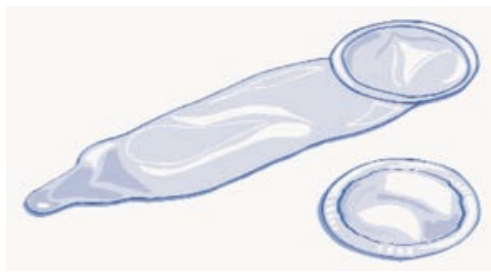

$\Rightarrow$ Nécessite la collaboration du partenaire (surtout pour les adolescentes qui souvent sont incapables de convaincre leur partenaire d'utiliser un préservatif);

$\Rightarrow$ Demande beaucoup de motivation et de volonté;

$\Rightarrow$ Entrâne une gêne de la part de certains adolescents à se le procurer ou à être vu avec des préservatifs;

$\Rightarrow$ Entraîne dans de très rares cas des allergies au latex;

$\Rightarrow$ Peut s'abîmer lors des rapports sexuels s'il n'est pas de bonne qualité;

$\Rightarrow$ Est souvent associé à une sexualité immorale (en dehors du mariage).

\section{Quel est le mode d'emploi?}

Attendre que le pénis se durcisse (en érection);

$\Rightarrow$ Déchirer l'emballage avec soin au niveau de la marque prévue;

$\Rightarrow$ Sortir la capote de l'emballage;

$\Rightarrow$ Vérifier le bon côté pour la dérouler, il ne faut pas la dérouler avant de la mettre;

$\Rightarrow$ Pincer le bout de la capote et la placer sur le pénis en érection;

$\Rightarrow$ Tout en continuant de pincer le bout, dérouler la capote afin que le pénis soit entièrement couvert avant la pénétration;

$\Rightarrow$ Après l'éjaculation, se retirer avant que le pénis ne soit mou. Tenir la capote et le pénis en se retirant;

$\Rightarrow$ Enlever la capote avec un mouchoir en papier en s'assurant que le liquide reste bien à l'intérieur. Ne pas dérouler la capote;

$\Rightarrow$ Nouer le préservatif après en avoir chassé l'air, le jeter dans les toilettes ou l'enterrer profondément.

\section{Quels sont les lieux d'approvisionnement?}

Pharmacies;

Structures sanitaires notamment centres de Planification Familiale;

Certaines structures qui accueillent les jeunes, centres et bureaux conseils, associations qui pratiquent les Services à Base Communautaire, kiosques, boutiques etc... 
NB: Eviter les préservatifs vendus sur les étals des marchés, sur les trottoirs. Ils sont de qualité douteuse du fait de leur exposition au soleil. Les dates de péremption peuvent être dépassées...

\section{Qui peut utiliser la méthode?}

$\Rightarrow$ Tout individu qui ne souffre pas d'une allergie au latex;

$\Rightarrow$ Toutes les femmes capables de négocier l'emploi du préservatif avec leur partenaire.

\section{Conseils pratiques}

$\Rightarrow$ Il est important d'employer à chaque fois un préservatif;

$\Rightarrow$ Il faut bien conserver les préservatifs;

$\Rightarrow$ Employer toujours un autre préservatif si la qualité de celui que vous avez est douteuse (date de fabrication supérieure à 5 ans, couleur changée, desséché);

$\Rightarrow$ Voir le spécialiste en cas d'allergie ou d'autres problèmes liés à l'utilisation de la méthode.

\section{Réponses aux questions sur le préservatif}

\begin{tabular}{|l|l|l|}
\hline Croyances & \multicolumn{2}{|l|}{ Réponses } \\
\hline $\begin{array}{l}\text { Le préservatif } \\
\text { diminue le plaisir }\end{array}$ & Faux & $\begin{array}{l}\text { Le siège du plaisir sexuel se situe au niveau du cerveau. Physiquement, } \\
\text { le préservatif n'est pas un facteur de diminution ou d'inhibition du plaisir } \\
\text { sexuel. }\end{array}$ \\
\hline $\begin{array}{l}\text { Le VIH peut traverser } \\
\text { le préservatif }\end{array}$ & Faux & $\begin{array}{l}\text { Un préservatif en cours de validité et qui est bien conservé ne peut être } \\
\text { traversé par le VIH. }\end{array}$ \\
\hline $\begin{array}{l}\text { Il faut doubler le } \\
\text { préservatif pour être } \\
\text { bien protégé }\end{array}$ & Faux & $\begin{array}{l}\text { Le préservatif est fabriqué dans le respect des normes de qualités fiables. Il } \\
\text { n'est pas nécessaire de le doubler. }\end{array}$ \\
\hline $\begin{array}{l}\text { Le préservatif } \\
\text { diminue la virilité }\end{array}$ & Faux & $\begin{array}{l}\text { Il n'y a pas de lien entre l'utilisation du préservatif et l'augmentation ou non } \\
\text { de la virilité. }\end{array}$ \\
\hline $\begin{array}{l}\text { Le VIH est contenu } \\
\text { dans certains } \\
\text { préservatifs }\end{array}$ & Faux & $\begin{array}{l}\text { Le VIH est contenu dans le sang, le sperme, les sécrétions vaginales et le lait } \\
\text { maternel. Le préservatif neuf est totalement stérile. }\end{array}$ \\
\hline $\begin{array}{l}\text { Le préservatif se } \\
\text { déchire facilement. }\end{array}$ & Faux & $\begin{array}{l}\text { Le préservatif est fabriqué avec du latex qui est un matériau (matière) } \\
\text { résistant. Il est testé avant d'être mis sur le marché. Cependant, il faut } \\
\text { prendre des précautions quant à sa conservation et sa manipulation. Eviter } \\
\text { de l'exposer au soleil, de le garder dans la poche arrière d'un pantalon serré, } \\
\text { de l'ouvrir avec les dents, les ongles. }\end{array}$ \\
\hline $\begin{array}{l}\text { L'utilisation du } \\
\text { préservatif traduit un } \\
\text { manque de confiance }\end{array}$ & Faux & $\begin{array}{l}\text { L'utilisation du préservatif est plutôt un acte de responsabilité. Non seulement } \\
\text { c'est un moyen de protection contre les IST, mais aussi, il nous évite des } \\
\text { grossesses non désirées sources de beaucoup de problèmes. }\end{array}$ \\
\hline $\begin{array}{l}\text { Le préservatif est } \\
\text { réutilisable }\end{array}$ & Faux & \begin{tabular}{l} 
Le préservatif s'utilise une seule fois strictement. \\
\hline
\end{tabular} \\
\hline
\end{tabular}

\section{Le Dispositif Intra Utérin (DIU)}

Le Dispositif Intra Utérin communément appelé DIU est un petit appareil flexible en plastique avec des manchons de cuivre qui le recouvre partiellement. On le pose dans l'utérus de la femme. Il a un effet durable de près de 10 ans.

\section{Comment fonctionne t-il?}

Le DIU fonctionne en empêchant les spermatozoïdes et l'ovule de se rejoindre. Le DIU crée des difficultés aux spermatozoïdes qui veulent se déplacer dans l'appareil reproducteur et réduit la possibilité de féconder un ovule.

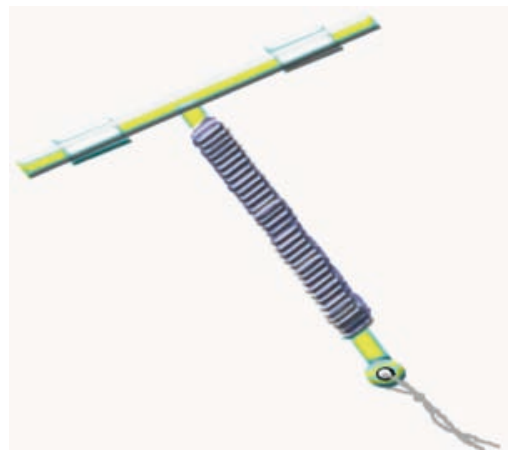




\section{Quels sont les avantages?}
$\Rightarrow$ Prévention à long terme (10 ans);
$\Rightarrow$ Très efficace;
$\Rightarrow$ Peu de choses à se rappeler;
$\Rightarrow$ Aucun effet secondaire hormonal avec les DIU en cuivre;
$\Rightarrow$ Réversible immédiatement;
$\Rightarrow$ Peut être posé aussitôt après un accouchement ou un avortement provoqué.

\section{Quels sont les inconvénients?}

$\Rightarrow$ Changements menstruels habituels pendant les 3 premiers mois;

$\Rightarrow$ Règles plus longues et plus abondantes;

$\Rightarrow$ Davantage de crampes ou de douleurs durant les règles;

$\Rightarrow$ Saignement entre les règles;

$\Rightarrow$ Ne protège pas contre les IST/VIH/SIDA;

$\Rightarrow$ Nécessité de vérifier régulièrement la position du fil dans le vagin;

$\Rightarrow$ Examen médical nécessaire;

$\Rightarrow$ La pose et le retrait nécessitent l'intervention d'un agent qualifié.

\section{Les spermicides:}

Ils se présentent sous forme de crème, de gel, de mousse, etc...

\section{Comment empêchent-ils la grossesse?}

Les spermicides sont des méthodes vaginales qui empêchent la grossesse en tuant les spermatozoïdes à leur entrée dans le vagin ou en les rendant incapables de féconder l'ovule.

\section{Quels sont les avantages?}

$\Rightarrow$ Sont sûrs (sauf rares cas d'allergies);

$\Rightarrow$ Sont faciles à utiliser avec un peu de pratique;

$\Rightarrow$ Protègent contre les IST d'origine bactérienne;

$\Rightarrow$ Ont peu d'effets secondaires.

\section{Quels sont les inconvénients et/ou effets secondaires?}

$\Rightarrow$ Irritation chez certains sujets et allergie en cas d'utilisation répétitive dans la journée;

$\Rightarrow$ Risque d'IST augmenté avec l'irritation;

$\Rightarrow$ Doit être utilisé au moment du rapport sexuel;

$\Rightarrow$ Demande un peu d'exercice pour être bien utilisé;

$\Rightarrow$ Ne protège pas de l'infection à VIH;

$\Rightarrow$ Conservation difficile (à conserver dans un endroit frais et sec).

\section{Quel est le mode d'emploi?}

Le spermicide est placé dans le vagin avant chaque rapport sexuel. Il doit être présent au niveau du col cervical. Après le rapport sexuel, la femme devra attendre au moins 6 heures avant de se doucher.

\section{Quels sont les lieux d'approvisionnement?}

Structures sanitaires notamment centres de PF;

$\Rightarrow$ Certaines structures qui accueillent les jeunes, centres, bureaux conseils, associations pratiquant les Services à Base Communautaire.

\section{Qui peut utiliser la méthode?}

Tout individu ne souffrant pas d'allergie aux spermicides. 


\section{Les methodes hormonales}

\section{Les contraceptifs oraux}

Appelés pilules, les contraceptifs oraux se répartissent en deux grandes catégories: les contraceptifs oraux combinés (COC) qui contiennent de l'œstrogène et un progestatif, et les pilules progestatives (PP). L'œstrogène et le progestatif contenus dans la pilule sont des produits synthétiques qui ressemblent aux hormones naturelles produites par la femme.

\section{Comment les contraceptifs oraux empêchent-ils la grossesse?}

$\Rightarrow$ Les contraceptifs oraux empêchent la grossesse en bloquant la libération de l'ovule par l'ovaire. Ils peuvent également épaissir la muqueuse cervicale rendant difficile le passage des spermatozoïdes dans l'utérus.

\section{Quels sont les avantages?}

$\Rightarrow$ Très efficace si la pilule est utilisée régulièrement et correctement;

Aucune répercussion sur la fertilité d'une jeune fille, même si auparavant elle n'avait jamais eu d'enfant;

$\Rightarrow$ Ne nécessite pas l'accord du partenaire;

$\Rightarrow$ Permet des rapports sexuels imprévus;

$\Rightarrow$ Régularise la menstruation;

$\Rightarrow$ Réduit le volume des règles, de même que les douleurs et crampes qui les accompagnent;

$\Rightarrow$ Réversible (si la femme désire une grossesse, elle arrête la prise de pilule);

$\Rightarrow$ A une action bénéfique pour la santé: atténuation de l'acné, protection contre la grossesse extrautérine, les maladie des seins, le cancer de l'ovaire...

\section{Quels sont les inconvénients et les effets secondaires?}

$\Rightarrow$ Il faut se souvenir quotidiennement et à horaire fixe de la prise de pilule;

$\Rightarrow$ Chez certains sujets: nausée, maux de tête, traces de règles entre les périodes (généralement ces manifestations diminuent après 3 mois d'utilisation), prise de poids;

$\Rightarrow$ Certaines pilules, notamment les COC (contenant de l'œstrogène) ne peuvent être utilisées par les femmes qui allaitent;

$\Rightarrow$ Il est préférable de passer un examen médical, avant de commencer à prendre la pilule, même si la pilule est vendue sans ordonnance en pharmacie;

$\Rightarrow$ Coûte relativement cher (on doit disposer d'une nouvelle plaquette tous les 28 jours);

$\Rightarrow$ Ne protège pas contre les IST/SIDA.

\section{Quel est le mode d'emploi?}

Chaque type de pilule a son propre mode d'emploi. Pour certains types, le paquet ou la plaquette contient 21 pilules qu'il faut prendre quotidiennement (une pilule par jour) pendant 21 jours, à la même heure et après avoir mangé. Lorsque les 21 pilules sont finies, la femme attend sept (7) jours avant de recommencer la prise. Pendant ces sept (7) jours de repos, elle doit normalement avoir ses règles.

$\Rightarrow$ D'autres plaquettes contiennent vingt huit (28) pilules, mais les dernières pilules ne contiennent pas d'hormones. Elles contiennent du sucre ou du fer. Dans ce cas, il n'y a pas d'interruption dans la prise des pilules. La période des règles coïncidera avec la prise des sept (7) dernières pilules inactives.

\section{Quels sont les lieux d'approvisionnement?}

Pharmacies;

Structures sanitaires notamment les centres de PF;

Structures d'accueil spécialisées: centres, bureaux conseils. 


\section{Qui peut utiliser la méthode?}

$\Rightarrow$ Toutes les femmes à l'exception de celles qui ont une contre-indication médicale comme les fumeuses, les femmes avec une hypertension chez qui l'utilisation de la pilule peut avoir des conséquences néfastes.

\section{Les contraceptifs injectables}

Les contraceptifs injectables contiennent des hormones semblables à la progestérone produite naturellement par l'organisme de la femme.

\section{Comment les contraceptifs injectables empêchent-ils la grossesse?}

Ils agissent de la même manière que la pilule, seul leur mode d'administration diffère. Les contraceptifs injectables bloquent l'ovulation. Ils épaississent également la muqueuse cervicale empêchant ainsi les spermatozoïdes de remonter dans l'utérus.

\section{Quels sont les avantages?}

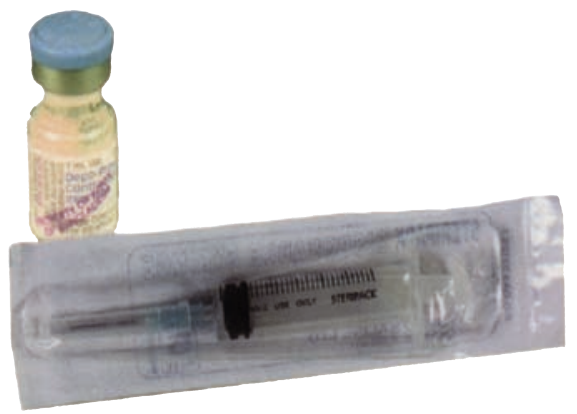

Très efficaces et sûrs;

$\Rightarrow$ Respect de l'intimité (on n'a pas besoin de l'implication du partenaire qui peut même ne pas être au courant);

$\Rightarrow$ Facile à utiliser (cependant, il ne faut pas oublier l'échéance pour une nouvelle injection);

$\Rightarrow$ S'accommode avec l'allaitement, protège contre certaines affections comme le cancer de l'endomètre, du col cervical et de la grossesse extra-utérine;

$\Rightarrow$ Ne nécessite aucun préparatif avant le rapport sexuel.

\section{Quels sont les inconvénients et les effets secondaires?}

$\Rightarrow$ Chez certains sujets, perturbation du cycle menstruel, irrégularité, traces de sang entre les périodes de règles, aménorrhée (absence des règles)...

$\Rightarrow$ Dans certains cas, prise de poids, maux de tête;

$\Rightarrow$ Retour à la fertilité retardée après l'arrêt des injections (4 à 10 mois);

$\Rightarrow$ Risque théorique chez les femmes de moins de seize (16) ans à cause d'effet potentiel sur la masse osseuse, qui pourrait entraîner une tendance à l'ostéoporose lorsqu'elles seront plus âgées;

$\Rightarrow$ Injections doivent obligatoirement être faites par un professionnel après examen médical;

$\Rightarrow$ N'assure aucune protection contre les IST/SIDA.

\section{Quel est le mode d'emploi?}

$\Rightarrow$ Injection en intramusculaire par un professionnel (tous les 3 mois pour le Dépo-Provéra et tous les deux pour le Noristérat). Respecter scrupuleusement les échéances que l'on soit sexuellement active ou pas.

\section{Quels sont les lieux d'approvisionnement?}

Structures sanitaires notamment les centres de PF.

\section{Qui peut utiliser la méthode?}

$\Rightarrow$ En principe, n'importe quelle femme sauf avis médical contraire.

\section{Les implants}

Les implants les plus courants, connus sous leur nom de marque NORPLANT $®$, sont constitués de minuscules cylindres sous forme de bâtonnets qui contiennent de la progestérone artificielle.

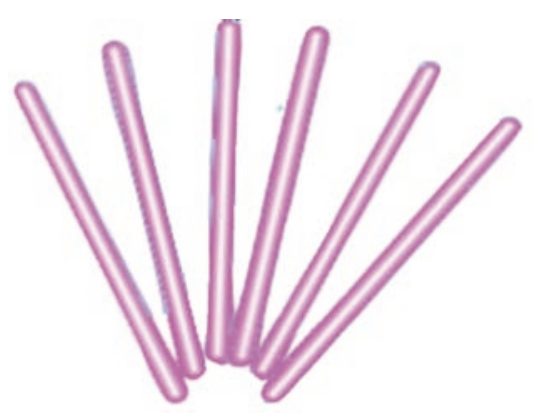




\section{Comment l'implant empêche-t-il la grossesse?}

$\Rightarrow$ Inséré sous la peau, dans le haut et à l'intérieur du bras, l'implant libère progressivement la progestérone qu'il contient dans l'organisme de la femme. Cette substance agit à trois (3) niveaux. Elle bloque l'ovulation dans la moitié des cas, épaissit la muqueuse cervicale empêchant ainsi les spermatozoïdes de pénétrer dans l'utérus et enfin dans certains cas, appauvrit l'alimentation de la paroi utérine de sorte que l'ovule fertilisé ne peut pas se développer.

\section{Quels sont les avantages?}

Sûr et efficace sur une longue période de cinq (5) ans;

$\Rightarrow$ Pas de risque d'erreur;

$\Rightarrow$ Réversible (il suffit de faire retirer l'implant par un professionnel);

$\Rightarrow$ Aucun préparatif avant le rapport sexuel;

$\Rightarrow$ Assure l'intimité (aucune implication du partenaire);

$\Rightarrow$ Protège contre l'anémie, la grossesse extra-utérine et dans certains cas contre le cancer de l'endomètre;

$\Rightarrow$ S'accommode de l'allaitement (commencer six (6) mois après l'accouchement).

\section{Quels sont les inconvénients et les effets secondaires?}

$\Rightarrow$ Perturbation du cycle menstruel généralement les trois (3) premiers mois: irrégularité des règles, abondance, prolongement voire absence totale de règles (aménorrhée);

$\Rightarrow$ Ne peut être entamé ni arrêté sans le recours à un professionnel;

$\Rightarrow$ Chez certains sujets, on a relevé des maux de tête, des vertiges, des nausées, une prise de poids et le développement de kyste au niveau de l'ovaire. Cependant, ces effets s'estompent avec le temps;

$\Rightarrow$ Coûteux;

$\Rightarrow$ Requiert une petite intervention chirurgicale pour placer et retirer le produit;

$\Rightarrow$ N'assure aucune protection contre les IST.

\section{Quel est le mode d'emploi?}

Un professionnel formé à cet effet, insère sous la peau, en haut et à l'intérieur du bras de la femme, l'implant. L'efficacité du produit est de cinq (5) ans.

\section{Quels sont les lieux d'approvisionnement?}

Structures sanitaires notamment celles qui fournissent des services en Santé de la Reproduction.

\section{Qui peut utiliser la méthode?}

$\Rightarrow$ N'importe quelle femme, jeune ou âgée, qui a ses règles, sauf avis médical contraire.

\section{(1) La contraception d'urgence}

Elle signifie l'utilisation de contraceptifs, pour prévenir la grossesse après un rapport sexuel non protégé. Beaucoup de jeunes ne connaissent pas cette méthode, alors qu'elle revêt une importance particulière pour eux parce que dans la plupart des cas, les rapports sexuels sont occasionnels et non protégés.

Cependant, la contraception d'urgence n'est pas considérée comme une méthode classique de contraception. Après avoir eu recours à elle, il faut adopter ou reprendre une méthode régulière si l'on veut se prémunir contre la grossesse.

\section{Comment empêche-t-elle la grossesse?}

On utilise les pilules contraceptives d'urgence après un rapport sexuel non protégé. La prise de ces produits a pour effet d'inhiber l'ovulation ou de la retarder. Elle pourrait également entraver la fécondation ou la nidation. Les contraceptifs d'urgence ne sont pas des produits abortifs: ils ne font pas avorter. Dès que la nidation a lieu, ils sont inefficaces. 


\section{Quels sont les avantages?}

$\Rightarrow$ Très efficace si elle est utilisée le plus tôt possible après un rapport sexuel non protégé;

$\Rightarrow$ Sûre pour toutes les femmes particulièrement celles qui ne prennent pas de contraceptifs oraux;

$\Rightarrow$ Peut-être utilisée si on ne veut pas tomber enceinte après un rapport sexuel non protégé.

\section{Par exemple:}

$\Rightarrow$ Si le condom est troué durant le rapport sexuel;

$\Rightarrow \mathrm{Si}$ aucune autre méthode contraceptive n'est utilisée;

$\Rightarrow$ Le rapport sexuel n'est pas planifié ou est forcé (viol);

$\Rightarrow$ La prise de la pilule a été oubliée.

\section{Quels sont les inconvénients et les effets secondaires?}

$\Rightarrow$ Nausée chez la moitié des femmes;

$\Rightarrow$ Vomissements;

$\Rightarrow$ Vertiges;

$\Rightarrow$ Maux de tête.

\section{Quel est le mode d'emploi?}

$\Rightarrow$ La première pilule dans les soixante douze (72) heures suivants un rapport sexuel non protégé;

$\Rightarrow$ La deuxième douze (12) heures plus tard.

L'efficacité est d'autant plus accrue que le produit est pris très tôt après le rapport sexuel.

\section{Quels sont les lieux d'approvisionnement?}

$\Rightarrow$ Pharmacies;

$\Rightarrow$ Structures sanitaires notamment celles qui fournissent des services de PF;

$\Rightarrow$ Services à base communautaire.

\section{Qui peut utiliser la méthode?}

$\Rightarrow$ N'importe quelle femme/fille sauf avis médical contraire.

\section{Les méthodes contraceptives définitives}

Il s'agit:

Chez la femme de la ligature des trompes;

Chez l'homme de la vasectomie.

\section{( La ligature des trompes}

C'est une intervention chirurgicale bénigne, sous anesthésie locale. L'ovulation n'est pas affectée, l'ovaire fonctionne normalement et libère de façon périodique un ovule. De ce fait, le désir sexuel n'est pas affecté.

\section{Comment la méthode empêche-t-elle la grossesse?}

Comme le nom l'indique, l'opération consiste à nouer ou alors à sectionner les trompes de Fallope empêchant ainsi l'ovule de s'acheminer dans celles-ci pour y rencontrer les spermatozoïdes.

\section{Quels sont les avantages?}

Méthode très efficace et sûre;

Opération bénigne, sous anesthésie locale;

Permanente;

Aucune répercussion sur le désir sexuel, l'aptitude. 


\section{Quels sont les inconvénients et/ou les effets secondaires?}

$\Rightarrow$ Irréversible, on ne peut pas revenir là-dessus (suppose une réflexion mûre et approfondie);

$\Rightarrow$ Gêne passagère après l'opération.

\section{Quel est le mode d'emploi?}

Opération chirurgicale pratiquée par un professionnel.

Dans quels lieux se pratique-t-elle?

Structures sanitaires.

\section{Qui peut utiliser la méthode?}

$\Rightarrow$ N'importe quelle femme le souhaitant.

\section{(1) La vasectomie}

\section{Comment la méthode empêche- t-elle la grossesse?}

L'opération consiste à sectionner le canal déférent, passage obligé des spermatozoïdes. S'il n'y a pas de spermatozoïdes, il n'y a aucune possibilité de fécondation de l'ovule.

\section{Quels sont les avantages?}

Efficace et sûre (cependant il faut au moins attendre vingt (20) éjaculations après l'opération ou un délai de trois (3) mois);

$\Rightarrow$ Opération bénigne, sous anesthésie locale;

$\Rightarrow$ Permanente;

$\Rightarrow$ Aucune répercussion sur le désir sexuel, l'aptitude.

Quels sont les inconvénients et/ou les effets secondaires?

$\Rightarrow$ Irréversible sauf dans de très rares cas (aussi mérite une réflexion mûre et approfondie);

$\Rightarrow$ Gêne passagère juste après l'opération.

\section{Quel est le mode d'emploi?}

Opération chirurgicale pratiquée par un professionnel.

\section{Dans quels lieux se pratique-t'elle?}

$\Rightarrow$ Structures sanitaires.

\section{Qui peut l'utiliser?}

Tout homme à priori.

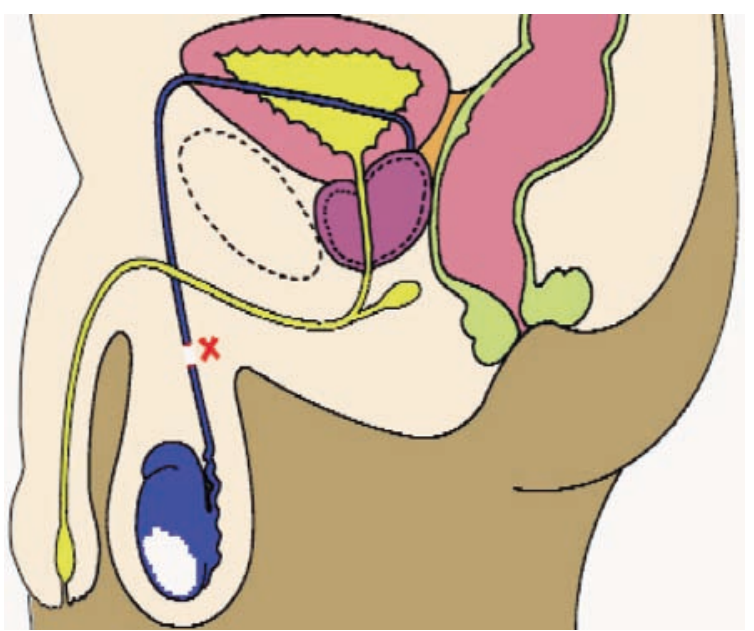




\section{Les Infections Sexuellement Transmissibles (IST)}

Les Infections Sexuellement Transmissibles (IST) sont transmises d'une personne à une autre par contact sexuel. Elles sont très fréquentes, mais sont souvent négligées, cachées et par conséquent mal soignées parce qu'elles sont souvent perçues comme des maladies honteuses. Les gens en parlent difficilement et pourtant, elles ouvrent la porte à l'infection au VIH responsable de la maladie du SIDA.

Les adolescent(e)s (10-19 ans) et jeunes adultes (20-24 ans), sont les groupes les plus exposés aux IST. A l'adolescence, le système reproductif et immunitaire est encore immature, ce qui expose les adolescent(e)s à diverses infections. Souvent les adolescent(e)s ont des rapports sexuels non protégés parce qu'ils ont souvent lieu dans un contexte de pression (exemple: rapport sexuel en échange d'argent, pression des pairs...). Les adolescent(e)s sont mal informés sur les IST; ils éprouvent de la crainte et de la gêne face au système médical et à l'attitude moralisatrice des prestataires. Ils évitent de se faire consulter ou attendent longtemps avant de le faire.

Avec les progrès réalisés dans le domaine de la médecine, de l'hygiène, il est possible maintenant de prévenir ces maladies, et quand elles surviennent de les traiter efficacement et réduire ainsi la propagation du SIDA qui reste pour le moment incurable.

\section{Définition:}

Une Infection Sexuellement Transmissible (IST) est une maladie qui se transmet d'une personne infectée à une autre personne non infectée le plus souvent lors de rapports sexuels non protégés (sans utilisation de préservatifs). Il existe plus d'une vingtaine d'IST dans le monde. On peut les classer selon le type d'affection:

(1) D'origine bactérienne (syphilis, chancre mou...);

() D'origine mycosique (candida...);

(1) D'origine parasitaire (trichomonas...);

(1) D'origine virale (SIDA, herpès, hépatites virales...).

On peut aussi les classer en deux catégories selon qu'elles sont incurables ou curables:

( Les IST incurables sont d'origine virale et si elles disparaissent temporairement, ça ne veut pas dire qu'elles sont guéries. Par exemple, le papillomavirus humain, l'hépatite B, l'herpès et le VIH sont des IST qu'on ne peut pas guérir;

(1) Les IST curables sont provoquées par des bactéries et disparaissent après un traitement antibiotique adéquat. Certaines IST d'origine bactérienne ont tendance à être sans symptôme apparent chez la femme. Elles sont donc difficiles à diagnostiquer.

ATTENTION: La plupart des gens ont des IST sans aucun signe apparent surtout chez la femme. On peut être infecté par plus d'une IST.

\section{Principaux signes des ist}

Les signes suivants peuvent être retrouvés chez l'homme et chez la femme:
() Douleurs en urinant;
(.) Fréquence des urines;
(.) Boutons sur la peau;
(1) Ecoulement génital;

() Difficultés pour uriner;

() Ganglions au niveau de l'aine;

() Plaies dans la bouche;

() Plaies sur le sexe (ces plaies peuvent être douloureuses ou non).

Chez l'homme, les IST peuvent se manifester par:

Un écoulement: liquide qui sort du sexe pouvant être du pus ou un liquide clair ressemblant au sperme. 
Chez la femme, les IST peuvent se manifester par:

() Des saignements irréguliers;

(1) Des douleurs au bas ventre;

(1) Des pertes vaginales anormales qui peuvent être blanches, jaunes, vertes mousseuses purulentes ou malodorantes;

(1) Des démangeaisons du vagin (l'individu se gratte le sexe);

() Des rapports sexuels douloureux.

\section{Principales ist}

() Syphilis;

(1) Gonococcie;

() Chancre mou;

(1) Infection à chlamydia;

Infection par le VIH/SIDA;

() Hépatite $\mathrm{B} / \mathrm{C}$;

(1) Herpès génital;

() Condylome;

(1) Trichomonas;

(.) Mycoses;

(1) Morpions;

() Gale.

\section{Attitudes à adopter en cas de ist}

\section{Ce qu'il faut faire en cas de IST}

() Pratiquer l'hygiène corporelle et vestimentaire;

- Informer les partenaires sexuels et les encourager à aller aux structures de santé pour se faire traiter;

(1) Eviter de se soigner soi-même;

() Utiliser des préservatifs pendant les rapports sexuels;

(1) Suivre le traitement correctement jusqu' au bout;

() Faire un examen de contrôle après le traitement;

(1) Demander à son ou sa partenaire de se faire traiter (pour éviter d'être à nouveau contaminé).

\section{Ce qu'il ne faut pas faire}

Certaines pratiques peuvent favoriser les IST:

(1) L'utilisation de certains produits tels que des poudres ou plantes dites aphrodisiaques;

(1) L'utilisation trop fréquente de produits antiseptiques pour la toilette intime;

(1) L'utilisation de certains médicaments sans l'avis des professionnels de santé ne guérit pas la maladie et peut provoquer des complications.

\section{Pour éviter d'avoir une IST, il faut:}

(1) S'abstenir de tout rapport sexuel;

(1) Etre fidèle à un partenaire non infecté;

() Utiliser toujours et correctement le préservatif.

\section{Les conséquences des ist}

( ) Les IST non traitées peuvent entraîner des complications telle que la stérilité chez l'homme ou chez la femme;

(1) Elles peuvent être des portes d'entrée du virus du SIDA;

() Une femme ayant une IST peut la transmettre à son enfant pendant la grossesse ou à l'accouchement. 


\section{Le VIH/SIDA}

Le SIDA est une maladie causée par un virus appelé Virus d'Immunodéficience Humaine (VIH) qui affaiblit les défenses du corps. Le Sida réduit ainsi la possibilité du corps de lutter contre les maladies.

\section{Notion de séropositivité}

\section{Qu'est-ce qu'une personne séropositive?}

Une personne séropositive est quelqu'un qui a le virus du SIDA dans le corps et qui ne présente aucun signe de maladie. Il est d'apparence bien portant. Il faut une analyse de sang pour savoir si une personne a le virus du SIDA ou non.

La personne séropositive peut apporter sa part de contribution dans la lutte contre la pandémie du SIDA en refusant:

() Tout rapport sexuel non protégé;

(.) De donner son sang et même peut-être d'avoir un enfant.

Les parents et amis d'une personne séropositive doivent lui

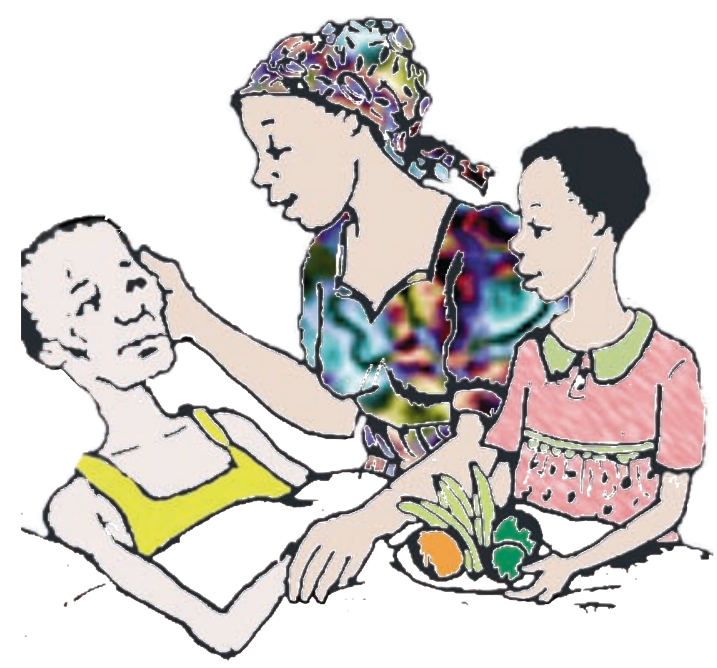
apporter leur appui et soutien tant sur le plan moral que matériel (en cas de besoin) et l'encourager à tout mettre en œuvre pour préserver la vie des autres par un comportement responsable.

\section{Les modes de transmission du sida}

Le virus du SIDA se transmet d'une personne infectée à une autre personne.

\section{Par voie sexuelle}

Lors des relations sexuelles non protégées, c'est à dire sans utilisation de préservatif.

\section{Par voie sanguine}

Lors de la transfusion sanguine si le sang transfusé est infecté;

(1) Lors de l'utilisation d'instruments piquants ou tranchants souillés par du sang infecté;

(2) Lors de certaines pratiques culturelles et traditionnelles telles que la circoncision, l'excision, la scarification, le tatouage...

\section{De la mère à l'enfant}

La mère qui a le virus du SIDA peut le transmettre à son enfant pendant:

(2) La grossesse, parce que le virus peut se trouver dans le placenta (enveloppe qui couvre l'enfant dans le ventre de sa mère);

(1) L'accouchement, s'il y a un mélange du sang de la mère et de l'enfant au niveau du cordon ombilical;

(.) L'allaitement, parce que le lait maternel contient le virus du SIDA chez une femme qui a le VIH.

\section{Ce qui ne transmet pas le sida}

(1) Serrer la main d'une personne séropositive;

(1) Partager les habits et les toilettes;

(1) Manger ensemble;

(1) S'asseoir côte à côte;

(1) Partager le même lieu de travail;

(1) Etre piqué par un moustique. 


\section{Pourquoi le moustique ne transmet-il pas le SIDA?}

\section{Argument 1}

- Les maladies transmises par les moustiques touchent toute la population (enfants, adultes, personnes âgées) indifféremment. Ceci n'est pas le cas avec le SIDA qui touche en grande partie les personnes jeunes et sexuellement actives;

(2) Dans les familles des personnes infectées, on ne trouve pas de personnes contaminées que chez les partenaires sexuels et des enfants nés de mères porteuses du virus. Si les moustiques transmettaient les virus, on l'aurait également retrouvé chez les autres membres de la famille;

\section{Argument 2}

() Le moustique ne transmet pas le virus du SIDA car le sang qu'il suce lorsqu'il pique une des personnes infectées, est digéré par son organisme et donc le virus est tué. Plus tard, lorsqu'il va piquer une autre personne, il va lui transmettre sa salive contenant uniquement le plasmodium (microbe qui transmet le paludisme) et non le virus du SIDA.

\section{Les signes du sida}

\section{Les principaux signes:}

(1) Une perte de poids très importante;

(1) Une diarrhée qui ne guérit pas malgré un traitement;

() Une fièvre.

\section{Autres signes:}

Une toux persistante (c'est à dire qui dure pendant des mois);

() Des démangeaisons;

(.) L'herpès (une IST) qui revient toujours;

(1) Des ganglions;

(1) Des pertes de mémoire;

(1) Une fatigue permanente;

(1) Une douleur chronique (localisée partout dans le corps).

Le SIDA est le stade final de l'évolution de l'infection à VIH. Il peut se manifester par un ensemble de maladies.

La maladie du SIDA est l'une des maladies sexuellement transmissibles qu'on ne peut pas guérir. Comme certaines IST, la personne peut avoir le virus du SIDA sans le savoir et le transmettre à d'autres personnes. Une personne infectée par le VIH peut continuer à vivre pendant des années avant de tomber malade.

Il faut faire un test de dépistage pour savoir si on est infecté par le VIH ou pas.

\section{Le conseil et le dépistage volontaires et anonymes}

Beaucoup de gens qui sont infectés par le VIH ne le savent pas parce qu'ils n'ont jamais fait le test de dépistage. Se faire dépister est la seule manière de savoir si on est infecté ou pas.

La manière la plus courante de faire le test est la prise de sang, mais il existe le prélèvement oral et le test d'urine qui sont disponibles dans certaines structures hospitalières. Dans certains hôpitaux et dans les Centres de Dépistage Volontaires et Anonymes (CDVA), on teste le sang pour savoir s'il contient des anticorps (substances produites par le corps pour lutter contre les microbes) au VIH. En effet, six semaines après la pénétration du VIH dans l'organisme, le corps fabrique des anticorps pour combattre le virus. 
Le résultat du test est soit positif, soit négatif:

Si le test est positif, cela signifie que la personne a le virus dans le corps, elle est infectée. La personne est séropositive, mais cela ne veut pas dire qu'elle développe la maladie du SIDA;

(1) S'il est négatif, cela veut dire que des anticorps du VIH n'ont pas été détectés indiquant soit que la personne n'est pas infectée par le VIH (elle est séronégative), soit qu'il est trop tôt pour savoir. En effet dans les trois mois qui suivent l'infection, les anticorps ne sont pas détectables car ils sont en faible quantité dans le sang. Cette période est appelée la séroconversion. Pour être absolument sûr, le test doit être fait deux fois à trois mois d'intervalle pour donner aux anticorps le temps de pouvoir apparaitre dans le sang.

Faire le dépistage du VIH inclus le counselling avant et après le test :

(1) Le counselling pré-test est un entretien individuel avec un conseiller qui explique la procédure du test et la façon dont le résultat va être donné. C'est l'occasion de poser des questions à propos du test et de partager ses craintes et ses questionnements. La personne décide si elle est prête pour le test ou pas;

(1) Lors du counselling post-test, le conseiller soutient la personne en lui donnant le résultat. Il doit s'assurer que la personne a bien compris la nature du résultat et lui permettre de s'exprimer sur la manière dont elle se sent. Si nécessaire, le conseiller aidera la personne à faire des prévisions immédiates et lui donnera les références pour les soins médicaux, des séances de counselling et des occasions de parler avec des personnes qui pourront l'aider à mieux comprendre le VIH/SIDA.

\section{Relations entre ist et vih}

Les IST avec ou sans plaie augmentent la transmission du VIH de deux façons:

(2) Quand une personne a une IST, il y a une porte d'entrée pour le VIH au niveau des organes génitaux;

(.) Quand une personne a une IST même sans plaie, il y a une inflammation c'est-à-dire que le corps prépare sa défense en envoyant du sang qui contient des globules blancs (soldats du corps). Ces globules blancs sont les cibles privilégiées du VIH qui les détruit et ainsi accélère l'installation de la maladie;

- Si la personne a une IST mais n'a pas le SIDA alors que son ou sa partenaire a le SIDA, le VIH libéré par ce dernier va directement attaquer ses globules blancs déjà affaiblis par l'IST;

( ) Si la personne a en même temps le SIDA et une autre IST, les virus contenus dans ses globules blancs vont directement passer chez son ou sa partenaire;

(1) L'infection à VIH a elle-même un effet sur les autres IST. Chez les individus ayant contracté le VIH, les manifestations de certaines IST sont plus importantes. Il est également reconnu que l'évolution de certaines IST est modifiée par le VIH. Le traitement des IST devient difficile chez les personnes vivant avec le VIH.

\section{Les conséquences socio-économiques du sida}

Le SIDA constitue un défi pour la société. A cause de son évolution fatale, il entraîne une charge pour la famille, la communauté et la société. Le SIDA a des conséquences incalculables tant sur le plan social qu'économique, aggravées par son évolution malgré tous les efforts tendant à limiter sa propagation.

\section{Prévention des ist/sida}

Les IST/SIDA ne sont pas une fatalité et sont des maladies tout à fait évitables. Les principaux moyens de prévention des IST/SIDA sont:

\section{L’abstinence}

C'est le seul moyen de protection efficace à 100\% pour prévenir les IST/SIDA. L'abstinence sexuelle hors mariage est une valeur centrale de notre société qui doit être vigoureusement promue parmi les adolescent(e)s.

\section{La fidélité}

La fidélité est un moyen de prévention des IST/SIDA. Dans une relation d'amour exclusive entre deux partenaires sains, une contamination par une IST n'est pas possible. Le fait d'avoir plusieurs partenaires augmente le risque de contamination par les IST, le VIH. La fidélité successive (à plusieurs partenaires successifs) n'est pas le type de fidélité qui peut prévenir les IST/SIDA. 


\section{Le préservatif}

L'usage correct du préservatif peut réduire le risque d'infection sans toutefois l'exclure. Un préservatif défectueux ou mal utilisé réduit l'efficacité de la protection. Le préservatif doit être bien conservé et bien utilisé pour garantir son efficacité.

\section{Utilisation d'instruments stériles ou à usage unique}

L'utilisation d'instruments piquant ou tranchant par une seule personne et à une seule fois si possible peut réduire le risque d'infection par le VIH. L'utilisation d'instruments qui n'ont pas été stérilisés ou plongés dans de l'eau de javel est à déconseiller.

\section{Ne pas toucher à la drogue et à l'alcool}

Les drogues et l'alcool modifient la faculté de jugement et la maîtrise de soi, ce qui peut conduire parfois à des rapports sexuels non protégés. Dans le cas de la prévention des IST, particulièrement du SIDA, l'abstinence de toute drogue et de l'alcool est d'une importance capitale.

\section{Test du VIH}

Comme le SIDA n'est pas guérissable, il est vivement recommandé d'effectuer un test VIH afin de déceler toute contamination. 